Portland State University

PDXScholar

Civil and Environmental Engineering Master's

Project Reports

Fall 2020

\title{
An Equity Focused Study on the Trip Temporal Distributions of Vulnerable Road Users
}

Santiago Espinosa Wild

Portland State University

Follow this and additional works at: https://pdxscholar.library.pdx.edu/cengin_gradprojects

Part of the Civil and Environmental Engineering Commons, and the Transportation Commons Let us know how access to this document benefits you.

\section{Recommended Citation}

Espinosa Wild, Santiago, "An Equity Focused Study on the Trip Temporal Distributions of Vulnerable Road Users" (2020). Civil and Environmental Engineering Master's Project Reports. 53.

https://doi.org/10.15760/CCEMP.53

This Project is brought to you for free and open access. It has been accepted for inclusion in Civil and Environmental Engineering Master's Project Reports by an authorized administrator of PDXScholar. Please contact us if we can make this document more accessible: pdxscholar@pdx.edu. 
An Equity Focused Study on the Trip Temporal Distributions of Vulnerable Road Users

BY

SANTIAGO ESPINOSA WILD

A research project submitted in partial fulfillment

of the requirement for the degree of

\section{MASTER OF SCIENCE}

IN

\section{CIVIL AND ENVIRONMENTAL ENGINEERING}

Project Advisor:

Dr. Kelly Clifton

Portland State University

(C) 2020 


\section{ACKNOWLEDGEMENTS}

I am extremely grateful to my supervisor Dr. Kelly Clifton for her invaluable guidance and support. Her assistance in formulating my research questions, finetuning my methodology, and interpreting my analysis was critical. Her insights about how and when people travel helped take this project into the next level.

I would also like to recognize my beautiful wife, Meara Espinosa, who supported and encouraged me throughout this entire process. She is very brave and hardworking and an excellent mom to our newborn twins Tomás and Jeffrey.

Finally, I want to thank my parents, who instilled in me the importance of perseverance and patience. 


\begin{abstract}
The United States is a megadiverse nation with a transportation system that, for decades, was designed to serve primarily able-bodied, white, male motorists. This legacy creates a situation in which varying sociodemographic groups experience the transportation system differently with contrasting safety, accessibility, and convenience outcomes. This project introduces descriptive statistics and binary logistic models that provide transportation professionals and policy makers with a quantitative understanding on how, why, and when certain socio-demographic groups are more likely to engage in a trip. This project provides tools to measure and understand the equity implications of a wide array of transportation policy decisions.

The binary logistic models presented predict the likelihood of a trip maker engaging on a weekday trip at a given time of day based on their race and ethnicity, gender, income level, preferred mode of transportation, age, and the purpose of their trip. In some instances, the interactions among these parameters were explored too. The models and descriptive statistics are based on the 2017 National Household Travel Survey data which includes over 900,000 datapoints and is weighted to adequately represent every socio-demographic group present in the U.S.
\end{abstract}




\subsection{INTRODUCTION}

\subsection{Background}

The United States is a diverse nation with an aging population composed of people of numerous races and ethnicities, who belong to a wide range of income brackets and for which at least half does not identify as male (US Census; Roberts et al., 2018 ; Semega et al., 2020). Everyone in each of these sociodemographic groups has the need to travel to reach a workplace, visit friends and family, shop and run errands or simply to return home to rest. These trip makers use some or all components of the transportation system available in their communities depending on whether they drive, walk, bike or take public transportation on their day-to-day lives. Although everyone uses the same transportation system composed of roadways, sidewalks, side paths and transit networks, not everyone's experiences are the same. Trip makers experience the transportation system differently with contrasting safety, accessibility, and convenience outcomes depending on the socio-demographic groups to which they belong. These inequities are directly attributable to the fact that the US transportation system prioritizes the needs of some socio-demographic groups over the needs of other groups.

In the past, transportation resources were allocated in a way that disproportionally served body-able white men using personal motor vehicles at the expense of minorities, women, and those with the lowest incomes who disproportionally walk, bike and use public transportation (Bullard, 2004; Clark, 2017, Wachs, 1987) and in detriment of vulnerable road users such as the elderly and children who stand to benefit the least from the dominant auto-centric transportation system. We believe that future transportation systems must break from the past and favor transportation solutions that serve a wider array of socio-demographic groups and are more equitable. The results of this project will aid in the design of infrastructure that avoids serving one socio-demographic group at the expense of others and is as equitable as possible.

This project explores a trip maker's temporal distributions based on their race-ethnicity, gender, income bracket, age, preferred mode of transportation, and the trip purpose behind every trip. This is achieved by first creating trip temporal distribution plots for every group and then by running a series binary logistic regression models for different times of day in which every variable in every parameter is studied. These binary logistic models allow us to examine the differences from one income bracket to another, from one race among others. Additionally, these models allowed to study the interactions between two parameters. Since the bulk of trips occur during weekdays and our dataset did not provide adequate information regarding trips during weekend days, this project will only analyze trips occurring on weekdays. Finally, we studied 4 equity related questions that were developed after studying the literature available on transportation equity as well as our results obtained on both the binary logistic models and the descriptive 
statistics. The questions were analyzed by tailoring the binary logistic models to answer the specific question being posed by isolating only the relevant parameters and their interactions.

The questions studied were:

1) How does race and income impact the afternoon travel of underage trip makers?

This is important question because, as we are going to see later on the literature review, children, are very vulnerable road users which can attribute a significant proportion of their overall fatalities and severe injuries to crashes with motor-vehicles. These fatalities occur either as a passenger of a motor-vehicle, or as a pedestrian or cyclists that collide with a motor-vehicle in the road. The literature also states that non-whites are at significantly more risk from being seriously or fatally injured when engaging with the transportation system and that the most dangerous time for children trip makers is in the afternoon around 15:00 hrs. perhaps because school end times are close to this time and students are free to return home. For these reasons, we though it worthwhile to study the interactions of race, mode of transportation, and young age when it comes to trips done between 13:30 and 18:00 on weekdays.

2) Do race and income play a role in determining whether someone travels early in the morning and what transportation mode they use?

Early morning trips are often related to non-professional jobs that do not follow the traditional 9am to 5pm office schedule or to shift jobs that either end or start early in the morning. These trips are undertaken when it is dark outside and it is particularly dangerous to use the road system, and at a time period that is typically not served by transit. The literature shows that the lack of natural or artificial lightning is a major contributor to fatal and serious collisions (FHWA, 2012; Nambisan, 2009). For this analysis, we looked only at trip makers that have a household income of $\$ 49,999$ a year or less, as they are the most likely to be transit dependent and have the least ability to switch jobs easily. We recognize that $\$ 49,999$ is a substantial household income but given that the average annual cost of a motor-vehicle is $\$ 9,282$ (AAA, 2019) we believe that even trip makers in that income bracket would benefit greatly from amenities improved such as early-morning transit or improved street lighting when engaged in a trip that early in the day. 
3) Is there a difference along gender lines on afternoon travel?

As we will see in the literature review, even in this day and age, women are more likely than men to be in charge of caregiving and homemaking tasks which differentiates their trip temporal distributions from those of men. This phenomenon is especially marked during the school pick-up times and after business hours when women are more likely to be in charge of picking up children at their schools and running household related errands. We want to examine the separated as well as the combined impacts of gender and trip purpose has on a trip maker to assess to what extent gender alone predicts the differences in travel behavior and to what extent trip purpose plays a role.

4) How do adults over the age of 65 differ in their nighttime and early morning travel along race lines?

Finally, this question deals with the trip temporal distributions of a very vulnerable group of road users: older adults. Specifically, we wanted to isolate the trip temporal distributions of older adults that due to their mode choice, race, and time of travel are at a particularly high risk. We selected the time block from 9pm to $7 \mathrm{am}$ because this is a time period in which there is little or no sunlight in large swaths of the US. As previously mentioned, the lack of light increases the risk of serious of fatal injuries for all road users. Since race, age, mode choice, and travelling when is dark outside play important roles in determining how safe a trip maker is when using the transportation system, we wanted to take a closer look at the trip temporal distributions and the role race and mode choice play in impacting the trip temporal distributions of older adults. This knowledge may aid in the design of policies that provide additional safety protections to this population.

We hope that the descriptive statistics and models developed in this project aid in the development of a more inclusive transportation policies by helping both transportation professionals and policy makers in acquiring a clearer understanding on how their transportation decisions impact a wide array of trip makers.

\subsection{Research Contribution}

This project is unique in that it examines equity related questions based on the trip temporal distributions of a variety of trip makers. Typically, equity questions are examined from a spatial point of view. Topics such as the presence and quality of safe transportation infrastructure in minority populated neighborhoods 
(Schmitt, 2020; Yu, 2014 ), transit coverage in areas where low income individuals and minorities reside (Giuliano,2003) and the inability of older adults to navigate auto dominated environments (SGA, 2014) among many others are commonly examined. However, the literature regarding the connection between equity in transportation and the diverse trip temporal distributions of these same groups is almost nonexistent.

We believe that this project makes a valuable addition to the literature in that it explores equity related questions regarding these same demographic groups from a temporal, instead of spatial, point of view. It not only introduces policy makers and even some transportation professionals to a new perspective when tackling equity related issues but offers a simple technique, in the form of constructing simple binary logistic regression models, to study the issue.

This project makes a valuable addition to the literature due to the innovative way it approaches equity related questions and due of its potential to be used as a blueprint to assess the equity of a variety of transportation policy decisions.

\subsection{LITERATURE REVIEW}

Transportation systems do not spring up out of thin air but are planned deliberately and only those with a seat at the table benefit from them. Decisions such as the frequency and coverage of transit lines, the alignment of current and future freeways and the overall quality of the bicycle and pedestrian infrastructure is often dictated by body-able white, affluent and often male decision makers who primarily rely on a motor-vehicle for transportation and who often fail to grasp and address the transportation needs of women, minorities, lower income people, users of non-motorized modes of transportation, children and the elderly (Bullard, 2004; Norton, 2008; Garrard,2012; Hoffman, 2016; Schmitt, 2020). This literature review will examine how these populations are not properly serviced by our existing transportation system. This review is divided in four subsections each for one of these socio-demographic categories: gender, race-ethnicity, income, and age. Although trip purpose and transportation mode are parameters studied in this project, we didn't dedicate them their own section in this review. This is because they are constantly mentioned when we reviewed the literature regarding the aforementioned categories.

\section{Gender}

There are two main themes throughout the literature that distinguish female trip makers from their male counterparts on deciding when and how to travel. Female trip makers show a greater concern for both 
crime related and traffic related safety and have household roles that make their travel patterns different from those of male trip makers. "The transportation literature consistently documents that as a results of differing household roles, women have tighter time budgets and more complex travel patterns and make more serve-passenger trips than men (Garrard, 2007)." Women avoid transportation modes such as bicycles due to the perceived traffic related dangers from using that mode and avoid nighttime travel to avoid being the victims of crime. (Emond, 2009; Singleton, 2016; Garrard, 2007; Dill., 2014; Clifton., 2004).

Women and men have different travel behaviors which are impacted by their different household roles. In two-worker households with kids it is the women who are more likely to be in charge of dropping off the kids before work, thus constraining their travel to whenever the school drop off time occurs. They make more trips than men but their trips tend to be of shorter duration and distance. Women tend to work closer from home than men and tend to make more short stops on their way to or from work a phenomenon called trip-chaining (McGuckin., 2005; Wachs,1987). Women display a greater reliance on nonautomobile transportation modes, and depending on factors such as employment status, age, and the number of children tend to do more nonwork trips such as family errands like shopping trips (McGuckin and Murakami., 1999; Vance., 2007). Finally, one study noted that women's travel peaks earlier on the day (Collins, 2002); however, it was not discussed if this was due to household demands, a simple preference to travel earlier on the day due to safety concerns, or any other reason.

\section{Race-Ethnicity}

This parameter plays an important role not only on a trip maker's trip temporal distribution but also in her safety and accessibility outcomes when engaging with the transportation system. The overwhelming lesson stemming from the literature is that African-American and Hispanic trip makers are at higher risk when using the transportation system. African Americans pedestrians have a fatality rate $60 \%$ higher than white pedestrians while Hispanic pedestrians have a fatality rate $43 \%$ higher than that of whites. Most alarmingly, American Indians and Alaskan Natives have a fatality rate almost 3 times higher than nonHispanic white trip makers at $267 \%$ (SGA, 2014). The literature offers several explanations for these disparities. One reason offered is simply than these groups tend to walk more than whites and that that increases their exposure (SGA, 2014). This increased exposure is due in part due to the fact that motorvehicle ownership and usage run at around \$9,282 annually (AAA, 2019), a high price tag for many but especially for those who are the most likely to live in poverty. African-American and Hispanic people are twice as likely than non-Hispanic whites to live in poverty and therefore rely more on walking and biking to complete their trips (Schmitt, 2020). Even when trip makers are not completing their entire journey by foot, they may rely on walking for parts of it as it is the case when trip makers walk to and from 
established transit lines. According to the Pew Research Center, African-Americans are more than 3 times more likely to use public transit than whites while Hispanics are twice as likely (Anderson, 2016).

Another reason offered is that African-Americans and Hispanics are more likely to live in urbanized areas and in areas with busy arterial roads that are inherently dangerous to pedestrians (SGA, 2014; Schmitt 2020). One study found that roadway design, especially if it encourages high traffic volumes, is the main culprit of injuries and fatalities in the roadway and notes that high traffic roads are more common in areas with lower incomes (Morency, 2012). As we noted before, blacks and Hispanics are more likely to experience poverty than non-Hispanic whites. The literature also points out that non-white trip makers rely more on transit than white trip makers and their households are spatially concentrated around urban areas and older suburbs (Giuliano, 2003). Entry-level jobs have moved away from urban areas into the suburbs and the exurbs which disproportionally impacts non-whites as it makes it more difficult for them to reach said jobs (Horner, 2007). This issue is further compounded as minorities have decreased access to motor-vehicles, a necessity if they are to travel to certain suburbs and exurbs. Additionally, non-whites are more likely to live closer, in terms of distance, to work than whites; however, they have longer commutes, in terms of time, than whites (Gautier, 2010).

Finally, two studies, one out of Portland, OR and the other out of Las Vegas, NV, found that drivers are less likely to yield to black pedestrians than they are to yield to white pedestrians (Coughenour, 2016). Blacks on average were passed by twice as many cars as whites before they could cross the street and had to wait around 30\% longer to wait the street (Goddard, 2014). This mistreatment on the part of motorists may be connected to the fact that African-Americans have higher pedestrian fatality rates than nonHispanic whites although that connection was not established.

\section{Income}

The main theme when it comes to the relationship between a trip maker's use of the transportation system and his income is one of access to a motor-vehicle and the ramifications stemming from being denied access to this transportation mode. As we mentioned on the previous section, motor-vehicle purchase and maintenance in the US runs upwards of $\$ 9,000$ a year, a staggering amount for someone living below the poverty line. This causes individuals with lower incomes to be more reliant on transit and walking for their day-to-day trips. Approximately $26 \%$ of low-income households do not have access to an automobile compared to $4 \%$ for all households and about $12 \%$ of low-income households have no drivers compared to $5 \%$ for all households. Individuals with lower incomes make about $5 \%$ of their trips using transit compared to $2 \%$ for trip makers with higher incomes. Individuals who use transit out of necessity, mainly because they don't own a car are commonly referred to in the literature as transit dependent and 
they represent the second largest market for transit after the downtown commuter. Transit dependent individuals tend to make numerous yet shorter than average transit trips than other transit users (Murakami, 1997; Giuliano 2003).

Two studies remarked that even though transit dependent individuals are an important constituency of every transit agency in the country they are often ignored as transit agencies devote their resources attracting choice riders who already have access to a motor-vehicle. This problem is compound by the fact that transit dependent individuals are predominantly low-income, minority riders who typically live in or near an urban core while the choice riders transit agencies seek to attract are predominantly white and live in suburban areas. This inequitable and often discriminatory distribution of resources has resulted in the creation of "transit deserts" in areas with significant latent demand for transit while tax monies are spent in areas with little potential for increase ridership (Garret, 1999; Jiao, 2013).

Age

The last parameter covered by this review is the trip maker's age. There are two age groups thar are particularly vulnerable when using the road system: children and the elderly. Children are more vulnerable due to their smaller size which makes them less visible to motorist and their lack of maturity which makes them more likely to behave unpredictably (Stevenson, 2015), older adults are more vulnerable due to their diminished sight, hearing and mobility which increases their exposure to roadway hazards (SGA, 2014).

Traffic crashes pose a grave risk to children. Crashes involving either motor-vehicle occupants or pedestrians or bicyclists, account for $66 \%$ of all unintentional injury deaths and $20 \%$ of all deaths in people below the age of 19 with male trip makers being at slightly higher risk than female ones (CDC, 2008; Schieber, 2002). Children under the age of 15 are at the most risk while walking and biking, with an annualized per person-trip rate more than double than the rate for children travelling inside a motorvehicle (Beck, 2007). The deadliest time of day for children using our transportation system is after school ends sometime around 3pm (Toran Pour, 2017; Sze, 2019).

Adults over the age of 65 have the highest annualized per person-trip fatality rate for the pedestrian and bicyclist category for all age groups and the second highest for drivers just behind people between the ages of 15 to 24 (Beck, 2017). Adults over the age of 65, just like children are more likely to walk and are more involved in vehicle against pedestrian crashes (Toran Pour, 2017; Sze, 2019). Unfortunately, these trends are only expected to get worse over time. The United States, thanks to longer life expectancies and lower birth rates, is considered an ageing nation and as the baby boomer generation, a particularly large cohort of people, keep on reaching the age of 65 pedestrian and bicyclist fatalities are expected to keep 
going up (Roberts, 2018; Schmitt, 2020). The number of adults over the age of 65 has increased from 35 million in the year 2000, to 49.2 million in 2016 (Roberts, 2018).

\subsection{METHODOLOGY}

The methodology for this project is divided into three sections. The first section deals with the modifications to the dataset that were necessary for its analysis, the second section deals with the trip temporal distribution plots and their construction, and the third one with the several binary logit models that are necessary for the study of specific equity related questions or the interaction of different variables belonging to distinct parameters.

First, a quick detour to explain what is the difference between a parameter and a variable. This project deals with only six parameters which are: race-ethnicity, gender, annual household income bracket, age, preferred transportation mode, and trip purpose. Each parameter contains several variables associated with it. For example, the gender parameter has two variables one called male and the other female. Table 1 shows the breakup for every variable and parameter included in this study.

Table 1: Parameters and variables analyzed

\begin{tabular}{|c|c|}
\hline Parameter Name & Associated variables \\
\hline Race-Ethnicity & $\begin{array}{l}\text { - } \text { non-Hispanic white } \\
\text { - } \text { Hispanic } \\
\text { - African-American } \\
\text { - Asians } \\
\text { - American Indians } \\
\text { - } \text { Pacific Islander }\end{array}$ \\
\hline Gender & $\begin{array}{ll}\text { - } & \text { Male } \\
\text { - } & \text { Female }\end{array}$ \\
\hline Annual Household Income Bracket & $\begin{array}{ll}\text { - } & \geq \$ 150,000 / \text { year } \\
\text { - } & \$ 125,000 \text { to } 149,999 / \text { year } \\
\text { - } & \$ 100,000 \text { to } 124,999 / \text { year } \\
\text { - } & \$ 75,000 \text { to } 99,999 / \text { year } \\
\text { - } & \$ 50,000 \text { to } 74,999 / \text { year } \\
\text { - } & \$ 35,000 \text { to } 49,999 / \text { year }\end{array}$ \\
\hline
\end{tabular}




\begin{tabular}{|c|c|}
\hline & $\begin{array}{l}\text { - } \$ 15,000 \text { to } 34,999 / \text { year } \\
\text { - } \leq \$ 14,999 / \text { year }\end{array}$ \\
\hline Transportation Mode & $\begin{array}{ll}\text { - } & \text { Motor-vehicle } \\
\text { - } & \text { Walk } \\
\text { - } & \text { Bike } \\
\text { - } & \text { Transit/ Public Transportation } \\
\text { - } & \text { School Bus }\end{array}$ \\
\hline Age & $\begin{array}{l}\text { - } 0 \text {-18 yrs. old } \\
\text { - } 18-30 \text { yrs. old } \\
\text { - } \quad 30-50 \text { yrs. old } \\
\text { - } \quad 50-65 \text { yrs. old } \\
\text { - } 65-80 \text { yrs. old } \\
\text { - } \quad 80 \text { yrs. old. }\end{array}$ \\
\hline Trip Purpose & $\begin{array}{ll}\text { - } & \text { Work } \\
\text { - } & \text { School } \\
\text { - } & \text { Errand/ Shopping } \\
\text { - } & \text { Social/ Recreation } \\
\text { - } & \text { Return Home }\end{array}$ \\
\hline
\end{tabular}

\section{Section 1: Dataset Modifications}

The dataset used for this study was the 2017 National Household Travel Survey. This survey contains data for the entire United States and contains a total of 923,572 datapoints or trips (FHWA, 2017). Since this project concentrates on weekday travel only we made use of only 570,543 datapoints. Each datapoint corresponds to an individual trip and contains information regarding the socio-economic characteristics of the trip maker such as race and ethnicity, gender, income bracket, mode of transportation, and trip purpose. Additionally, the data contains time stamps for every trip. It is important to note that the dataset does not include the date of each trip took; however, weekend and weekday trips are identified.

Due to the extensive level of detail included in the dataset some simplifications had to be done in order to streamline the analysis. The gender parameter was simplified to male, and female and those trip makers who did not choose one of these two options were grouped as other. The transportation modes were reduced from the 21 categories included in the dataset to just five categories: pedestrians, bicyclists, 
transit users, drivers of motorized vehicles and school bus users. Categories that were not directly related to intracity travel such as city-to-city bus or Amtrak trains were discarded. Table 2 shows how the available transportation modes from the survey were aggregated.

Table 2: Transportation Modes Analyzed

\begin{tabular}{|c|c|}
\hline Aggregated Mode & Modes from NHTS \\
\hline Pedestrian & - Walk \\
\hline Bicyclists & - $\quad$ Bicycle \\
\hline Transit & $\begin{array}{l}\text { - } \text { Public or commuter bus } \\
\text { - Subway/elevated/light rail/street car }\end{array}$ \\
\hline Motor-Vehicles & $\begin{array}{ll}\text { - } & \text { Car } \\
\text { - } & \text { SUV } \\
\text { - } & \text { Pickup truck } \\
\text { - } & \text { Van } \\
\text { - } & \text { Taxi/limo (including Uber/Lyft) } \\
\text { - } & \text { Motorcycle/Moped } \\
\text { - } & \text { Rental car (Zipcar/Car2Go) }\end{array}$ \\
\hline School Bus & - $\quad$ School Bus \\
\hline $\begin{array}{l}\text { Other modes (discarded } \\
\text { from study) }\end{array}$ & $\begin{array}{ll}\text { - } & \text { Something else } \\
\text { - } & \text { Airplane } \\
\text { - } & \text { Private/Charter/Tour/Shuttle Bus } \\
\text { - } & \text { Amtrak/Commuter rail } \\
\text { - } & \text { RV (motor home, snowmobile) } \\
\text { - } & \text { Golf cart } \\
\text { - } & \text { Paratransit } \\
\text { - } & \text { Boat/ Ferry / Water Taxi } \\
\text { - } & \text { City-to-City bus (Greyhound, Megabus etc.) }\end{array}$ \\
\hline
\end{tabular}

Another simplification was necessary when attempting to study trip makers and their demographic information. Since it is possible to have a person of Hispanic origins belong to any race category, we decided to study them together regardless of their race. The NHTS Survey allows each respondent to selfidentify as either Hispanic or non-Hispanic and as belonging to any of these race groups: White, Black or African American, Asian, American Indian or Alaska Native and Native Hawaiian or other Pacific 
Islander. Based on these NHTS categories we decided to create our own study demographic groups as shown in Table 3. Any demographic group not shown in that table was grouped under the label "other".

Table 3: Demographic Groups Analyzed

\begin{tabular}{|l|c|c|}
\hline \multicolumn{1}{|c|}{ Demographic Group } & Race & Hispanic or not. \\
\hline Non-Hispanic White & White & No \\
\hline Hispanic (any race) & Any & Yes \\
\hline African American & African American \\
\hline Asian & Asian & No \\
\hline American Indian or Alaska Native & American Indian or Alaska Native & No \\
\hline Native Hawaiian or other Pacific Islander & Native Hawaiian or other Pacific & No \\
& Islander & \\
\hline
\end{tabular}

An additional simplification was necessary to analyze the purpose of each trip. The NHTS data contains 20 different trip purposes but we are not interested in that level of detail. For that reason, we aggregated all trip purposes to fit into one of the 5 categories displayed on Table 4.

Table 4: Trip Purposes Analyzed

\begin{tabular}{|c|c|}
\hline $\begin{array}{l}\text { Aggregated Trip } \\
\text { Category }\end{array}$ & NHTS Trip Categories [origin or destination] \\
\hline Work & $\begin{array}{ll}\text { - } & \text { Work } \\
\text { - } & \text { Work-related meeting/trip }\end{array}$ \\
\hline School & - $\quad$ Attend school as a student \\
\hline Errands/Shopping & $\begin{array}{ll}\text { - } & \text { Buy goods (groceries, clothes, appliances, gas) } \\
\text { - } & \text { Buy meals (go out for a meal, snack, carry-out) } \\
\text { - } & \text { Other general errands (post office, library) } \\
\text { - } & \text { Buy services (dry cleaners, banking, service a car, etc.) } \\
\text { - } & \text { Health care visit (medical, dental, therapy) } \\
\text { - } & \text { Attend child care } \\
\text { - } & \text { Attend adult care }\end{array}$ \\
\hline Social/Recreation & $\begin{array}{ll}\text { - } & \text { Recreational activities (visit parks, movies, bars, etc.) } \\
\text { - } & \text { Exercise (go for a gog, walk, walk the dog etc.) } \\
\text { - } & \text { Visit friends or relatives } \\
\text { - } & \text { Religious or other community activities }\end{array}$ \\
\hline Return Home & - $\quad$ Regular home activities (chores, sleep) \\
\hline
\end{tabular}




\begin{tabular}{|l|l|}
\hline \multirow{2}{*}{ Other (Discarded) } & $\begin{array}{l}\text { Volunteer activities (not paid) } \\
\end{array}$ \\
& - Shange type of transportation \\
\hline
\end{tabular}

\section{Section 2: Trip Temporal Distribution Plots}

In order to crate these plots, the dataset had to be modified slightly on top of the data simplifications described on the previous section. First, we had to adequately weigh each trip. The National Household Travel Survey publishes individual weights for each reported trip. These weights take into account the demographic, economic and other applicable characteristics of the trip maker to ensure it is adequately represented in the survey. These weights correct for, among numerous other factors, the fact that trip makers from different socio-demographic groups are less or more likely to provide trip information to the NHTS and for the fact that not all areas of the country are sampled to the same extent. The weights are provided by the NHTS so in order to weight the data we simply have to use the weight linked to each individual trip instead of considering each datapoint as a 1-1 representation of the trips taking place on the field.

Second, each trip was assigned a time stamp in seconds equal to the database's time-of-day time stamp to simplify the analysis. The time stamp corresponds to the temporal midpoint of the trip. For example, a trip starting at 5:00pm and ending at 5:30pm would have a midpoint at 5:15pm and would be given a time stamp of 18,900 seconds. Using these times stamps each weekday trip was sorted into one of 48 bins each representing a half hour time-of-day increment. The percentage trips were calculated by dividing the sum of all the trips falling within each bin by the sum of weights for all trips considered. Table 5 , explains this with more detail.

Table 5: Trip Bins used

\begin{tabular}{|l|l|c|c|c|c|c|}
\hline $\mathrm{X}=$ & 00:00 to 00:30 & $\begin{array}{c}00: 30 \\
\text { to }\end{array}$ & $\begin{array}{c}01: 00 \\
\text { to }\end{array}$ & $\ldots$ & $23: 00$ to & 23:30 to 23:59:59 \\
& & $01: 00$ & $01: 30$ & & $23: 30$ & \\
\hline $\mathrm{Y}=$ & $\frac{\text { sum of weights all trips in bin }}{\text { sum of weights all weekday trips }} * 100 \%$ & idem & idem & $\ldots$ & idem & idem \\
\hline
\end{tabular}




\section{Section 3: Binary Logit Models without and with interaction terms.}

The final part of the project involves the creation of a series of binary logit regression models (Hosmer., Laneshow, Studivant, 2013). We decided to use this method because our data can be organized in a format usable by this form of statistical analysis and the output, an odds probability, is useful to compare different variables within the same parameter and to predict trip likelihoods for individual trip makers. With this statistical method, we are able to compare differences among, racial groups, genders, income brackets etc.

For this analysis, like we did with the trip temporal distribution plots, we concentrated on the same six parameters (race-ethnicity, gender, income bracket, age, mode of transportation and trip purpose) and on weekday travel only. The dependent variable in our models is a binary option stating whether or not the trip being analyzed occurred one of the nine time-blocks analyzed. For this analysis we divided the day into nine time-blocks that we believe contain trips with similar purpose and performed by similar people (early morning commute and school trips, mid-day errands, late afternoon commute back home, evening social trips etc.) Table 6 , shows these time blocks and the respective time of day they cover.

Table 6: Time blocks analyzed

\begin{tabular}{|l|l|}
\hline Time of Day Block & Time Span \\
\hline Early Morning & $00: 00$ to $04: 00$ \\
\hline Morning & $04: 00$ to $07: 00$ \\
\hline Peak Morning & $07: 00$ to $09: 00$ \\
\hline Late Morning & $09: 00$ to $11: 30$ \\
\hline Mid-Day & $11: 30$ to $13: 30$ \\
\hline Afternoon & $13: 30$ to $15: 00$ \\
\hline Peak Afternoon & $15: 00$ to $18: 00$ \\
\hline Evening & $18: 00$ to $21: 00$ \\
\hline Night & $21: 00$ to $23: 59: 59$ \\
\hline
\end{tabular}

Before running the binary logistical regression, we had to massage, using code written in $\mathrm{R}$ programming language, the original NHTS dataset into a format that SPSS, the software package used for our analyses, could use. Tables 7 thru 13 detailed how each variable analyzed was coded into the models. 
Table 7: Dependent Variable

\begin{tabular}{|l|l|}
\hline \multicolumn{1}{|c|}{ Code } & \multicolumn{1}{c|}{ Meaning } \\
\hline 1 & Trip occurred during the time-block analyzed \\
\hline 0 & Trip did not occur during the time-block analyzed \\
\hline
\end{tabular}

Table 8: First Independent Variable - Race and ethnicity

\begin{tabular}{|c|l|}
\hline Code & Race or ethnicity of trip maker \\
\hline 1 & non-Hispanic White \\
\hline 2 & Hispanic of any race \\
\hline 3 & African American \\
\hline 4 & Asian \\
\hline 5 & American Indian \\
\hline 6 & Pacific Islander \\
\hline 7 & Other \\
\hline
\end{tabular}

Table 9: Second Independent Variable - Gender

\begin{tabular}{|l|l|}
\hline \multicolumn{1}{|c|}{ Code } & Gender of trip maker \\
\hline 1 & Male \\
\hline 2 & Female \\
\hline 3 & Other \\
\hline
\end{tabular}

Table 10: Third Independent Variable - Income Bracket

\begin{tabular}{|c|c|}
\hline Code & $\begin{array}{l}\text { Annual Combined Household } \\
\text { Income of Trip Maker }\end{array}$ \\
\hline 1 & $>\$ 150,000$ \\
\hline 2 & $\$ 125,000-\$ 149,999$ \\
\hline 3 & $\$ 100,000-\$ 124,999$ \\
\hline 4 & $\$ 75,000-\$ 99,999$ \\
\hline 5 & $\$ 50,000-\$ 74,999$ \\
\hline
\end{tabular}




\begin{tabular}{|c|c|}
\hline 6 & $\$ 35,000-\$ 49,999$ \\
\hline 7 & $\$ 15,000-\$ 34,999$ \\
\hline 8 & $<\$ 14,999$ \\
\hline 9 & Other \\
\hline
\end{tabular}

Table 11: Fourth Independent Variable - Mode

\begin{tabular}{|c|l|}
\hline Code & Mode of Transportation \\
\hline 1 & Motor-Vehicle \\
\hline 2 & Walk \\
\hline 3 & Bike \\
\hline 4 & Transit \\
\hline 5 & School Bus \\
\hline 6 & Other \\
\hline
\end{tabular}

Table 12: Fifth Independent Variable - Trip Purpose

\begin{tabular}{|l|l|}
\hline Code & Trip Purpose \\
\hline 1 & Work \\
\hline 2 & School \\
\hline 3 & Errands/ Shopping \\
\hline 4 & Social/ Recreation \\
\hline 5 & Other \\
\hline
\end{tabular}

Table 13: Sixth Independent Variable - Age Bracket

\begin{tabular}{|c|l|}
\hline Code & Age [years old] \\
\hline 1 & $30-50$ \\
\hline 2 & $0-18$ \\
\hline 3 & $18-30$ \\
\hline 4 & $50-65$ \\
\hline 5 & $65-80$ \\
\hline 6 & $>80$ \\
\hline
\end{tabular}


After massaging the data, we ran a simple binary logistical regression using SPSS software. We used the unweighted NHTS dataset because the enormous amount of data the trip weights introduced could not be used by SPSS to produce usable results.

Note that in Table 13, the age brackets are not organized from the youngest trip makers to the older ones in a consecutive fashion. This is because, we wanted to use the trip makers between the ages of 30 and 50 as our baseline for most of our models because they are the peak of their work life and could serve as a benchmark to which compare all other age groups. Table 14 lists the baselines that were generally selected for our models, in some instances selecting a different baseline made the most sense to solve a specific question. In those cases, the tables containing the model results will clearly show what variable was used as a baseline.

\section{Table 14: Baselines Selected}

\begin{tabular}{|l|l|}
\hline \multicolumn{1}{|c|}{ Parameter Analyzed } & \multicolumn{1}{c|}{ Variable used as baseline } \\
\hline Race/Ethnicity & Non-Hispanic White \\
\hline Gender & Male \\
\hline Income Bracket & $>\$ 150,000$ \\
\hline Mode of Transportation & Motor-Vehicle \\
\hline Trip Purpose & Work \\
\hline Age Bracket & $18-30$ \\
\hline
\end{tabular}

Finally, a note on the power and fit of the model. We decided to use the Nagelkerke pseudo R square metric to measure the power of each model because its values ranged from 0 to 1 . This bears resemblance to the R square value commonly used to measure the power of a linear regression. Since we are the most familiar with this type of regression the use of the Nagelkerke pseudo R square made the most sense. Although the Nagelkerke pseudo R square is provided, the reader should bear in mind that the models provided are there to measure the travel odds of trip makers and not to provide a comprehensive travel forecasting model. For this reason, we are comfortable with low Nagelkerke pseudo R squares as long as the odds presented in the models are statistically significant. The other metric provided with the HosmerLemeshow goodness of fit. This metric indicates poor fit if the significance value is below 0.05 . 


\subsection{ANALYSIS}

As mentioned in the introduction this project is divided into two parts. The first one consists on an individual analysis of each of the six parameters considered in this project: race- ethnicity, gender, income bracket, age, trip purpose and transportation mode. This analysis includes both a plot displaying the weekday trip temporal distributions for all variables analyzed under each parameter and a table containing the odds, compared against a baseline, each variable has on increasing or decreasing the likelihood of travel.

The second part consists of several binary logistic regression models. These models are constructed to specifically answer 4 equity related questions that were constructed after both looking at the research presented on the literature review, the trip temporal distribution plots, and the impacts each variable has on increasing or decreasing the likelihood of travel for every parameter analyzed. Sometimes, when attempting to answer these equity related questions it makes sense to evaluate the combined effects of two parameters. Binary logistic models allow the researcher to look at the combined effects that any given two variables have on the trip temporal distribution of a given trip maker. These combined effects are often referred to as interactions.

\section{Individual Parameters.}

Recall that each parameter includes individual variables. For example, in the case of the race-ethnicity parameter we use the variables non-Hispanic white, Hispanic, African-American among others. Each of the next six sections will deal with one parameter at a time and will show both a plot of the trip temporal distributions for all variables studied under each parameter and a table showing the odds a trip maker belonging to the group described under each variable has of engaging on a trip on the time period being analyzed. These odds are compared against a baseline. For example, in the case of the race-ethnicity parameter we use non-Hispanic whites as our baseline for which all other race-ethnicity groups are compared against. These odds were obtained from one of the nine binary logistic regression models shown in Appendix A.

\section{Findings by race}

This analysis showed that a trip maker's race and ethnicity have a substantial impact on his or her trip temporal distribution, with the US's four largest race-ethnicity groups displaying noticeably different trip temporal distributions. Figure 1 displays these distributions. As you may have noticed we didn't include American Indians and Pacific Islanders in our plot. We decided to concentrate in just the four larges raceethnicity groups since the level of significance, or p-value, for American Indians and Pacific Islanders 
was considerably above 0.05 when we ran these variables in every binary logit model we ran. Table 15 shows the effects every variable has.

Table 15: Odds of travel on different time-of-day periods by race-ethnicity

\begin{tabular}{|l|c|c|c|c|c|c|c|c|c|c|}
\hline & $\begin{array}{c}\text { Early } \\
\text { Morning }\end{array}$ & Morning & $\begin{array}{c}\text { Peak } \\
\text { Morning }\end{array}$ & $\begin{array}{c}\text { Late } \\
\text { Morning }\end{array}$ & $\begin{array}{c}\text { Mid- } \\
\text { day }\end{array}$ & Afternoon & $\begin{array}{c}\text { Peak } \\
\text { Afternoon }\end{array}$ & $\begin{array}{c}\text { Evening } \\
\text { Night }\end{array}$ \\
\hline Non-Hispanic White & \multicolumn{7}{|c|}{ Baseline } \\
\hline Hispanic any race & $\mathbf{1 . 3 2 9}$ & $\mathbf{1 . 2 4 8}$ & 1.045 & $\mathbf{0 . 9 0 8}$ & $\mathbf{0 . 9 2 1}$ & 0.937 & $\mathbf{0 . 9 7 0}$ & $\mathbf{1 . 1 1 0}$ & $\mathbf{1 . 2 1 0}$ \\
\hline African-American & $\mathbf{2 . 0 9 5}$ & $\mathbf{1 . 2 4 9}$ & 1.033 & $\mathbf{0 . 8 9 6}$ & $\mathbf{0 . 9 1 5}$ & 0.983 & $\mathbf{0 . 9 6 3}$ & $\mathbf{1 . 1 2 5}$ & $\mathbf{1 . 2 7 8}$ \\
\hline Asian & 1.189 & $\mathbf{0 . 7 9 4}$ & 1.030 & 1.024 & $\mathbf{0 . 9 2 4}$ & 0.970 & $\mathbf{0 . 9 2 7}$ & $\mathbf{1 . 2 2 1}$ & $\mathbf{1 . 2 0 4}$ \\
\hline American Indian & 1.216 & 1.129 & 1.089 & 1.069 & 0.928 & 1.015 & 0.933 & 1.002 & 1.057 \\
\hline Pacific Islander & 1.525 & 1.142 & 1.267 & 0.859 & 0.854 & 1.014 & 0.936 & 0.944 & $\mathbf{1 . 6 3 9}$ \\
\hline
\end{tabular}

Bold lettering denotes that the variable is significant

\section{Weekday Trips by Race and Etnicity}

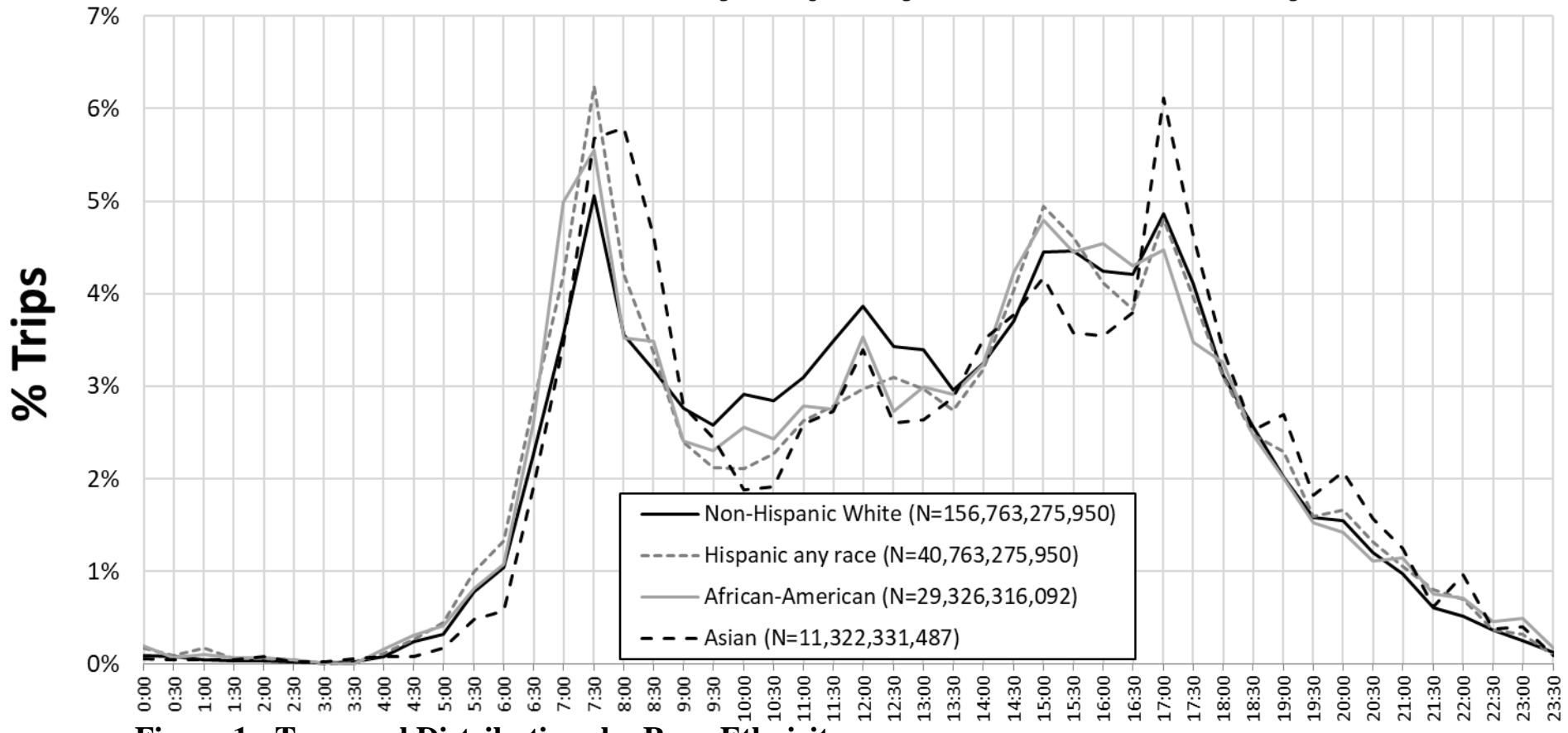

Figure 1: Temporal Distributions by Race-Ethnicity 
Overall, these are the most obvious trends coming out from our analysis:

- Non-Hispanic whites have a relatively small trip temporal distribution morning peak and tend to travel more during the middle of the day compared to other groups. Their odds of engaging on a trip during the late-morning, mid-day and afternoon are substantially higher than those of Hispanics and African Americans.

- African-American and Hispanic trip makers make a larger proportion of their trips during nighttime hours than either Asians and non-Hispanic whites. This means that they are using the transportation system when there is little or no sunlight. The odds of these groups travelling are particularly high during the early-morning and morning periods.

- African-American and Hispanic trip makers make a larger proportion of their trips around 15:00 hours. We can appreciate this from the trip temporal distribution plot shown in Figure 2.

\section{Findings by Gender}

We observed that gender plays an important role in a trip maker's trip temporal distribution. As shown in Figure 2 women are more likely than men to travel during the middle of the day and men at night or early in the morning. Most importantly, women have a peak in their trip temporal distributions around 15:00 hrs. that men do not. These findings are confirmed by the odds presented in Table 16. Note that this analysis does not include people who do not identify as either male or female, this is because the NHTS groups all people who don't identify with one of these genders as "other" without providing any additional information. 


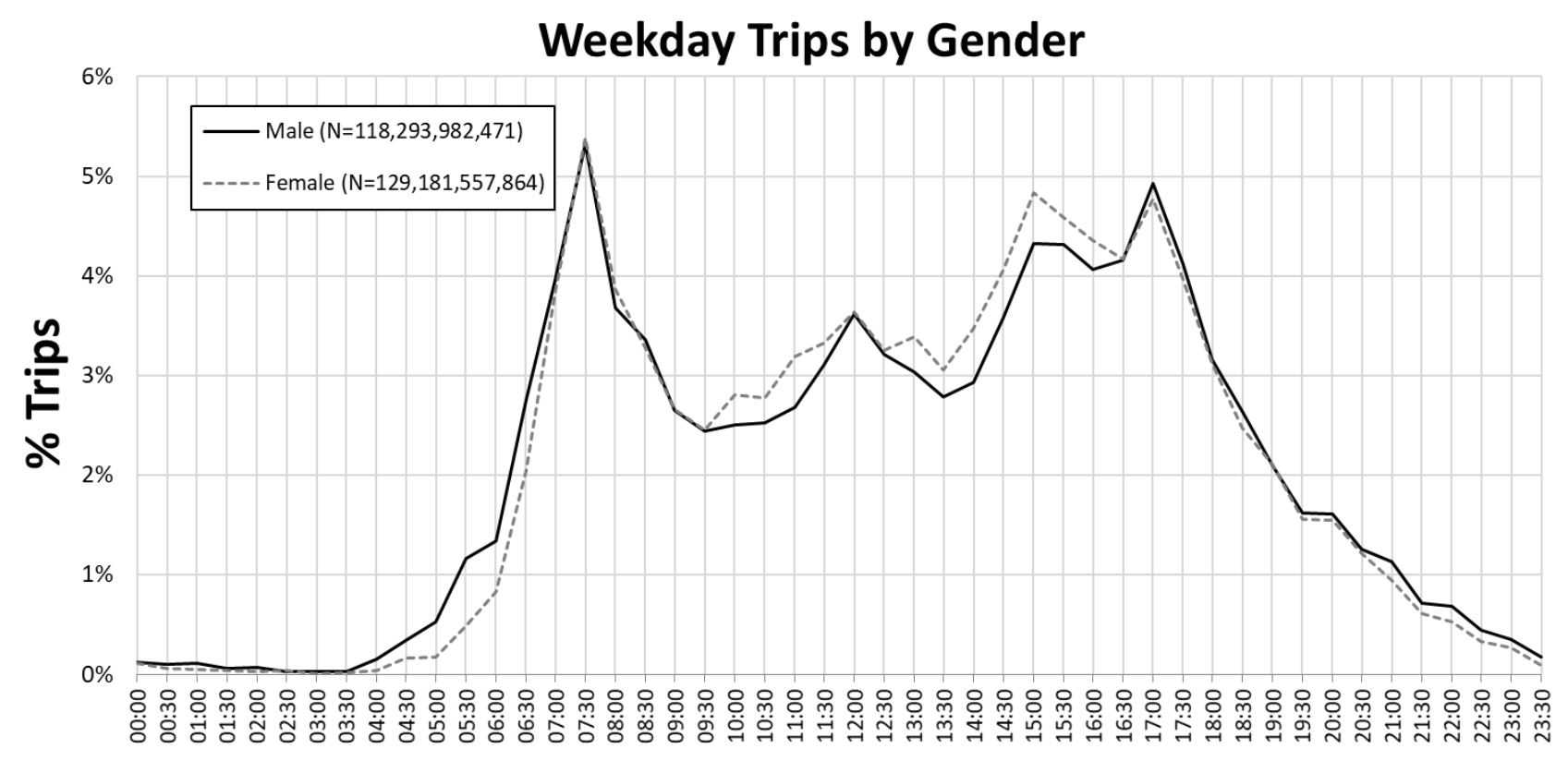

Figure 2: Temporal Distributions by Gender

Table 16: Odds of travel on different time-of-day periods by race-ethnicity

\begin{tabular}{|l|c|c|c|c|c|c|c|c|c|}
\hline & $\begin{array}{c}\text { Early } \\
\text { Morning }\end{array}$ & Morning & $\begin{array}{c}\text { Peak } \\
\text { Morning }\end{array}$ & $\begin{array}{c}\text { Late } \\
\text { Morning }\end{array}$ & $\begin{array}{c}\text { Mid- } \\
\text { day }\end{array}$ & Afternoon & $\begin{array}{c}\text { Peak } \\
\text { Afternoon }\end{array}$ & Evening & Night \\
\hline Male & \multicolumn{10}{|c|}{ Baseline } \\
\hline Female & $\mathbf{0 . 5 2 0}$ & $\mathbf{0 . 6 1 9}$ & $\mathbf{1 . 1 4 4}$ & 1.011 & $\mathbf{1 . 0 4 6}$ & $\mathbf{1 . 1 2 0}$ & $\mathbf{1 . 0 1 3}$ & $\mathbf{0 . 9 2 8}$ & $\mathbf{0 . 8 3 4}$ \\
\hline
\end{tabular}

Bold lettering denotes that the variable is significant

\section{Findings by Income}

We analyzed the trip temporal distributions of trip makers belonging to eight different income brackets. As our analysis progressed, we noticed that while the trip temporal distributions of those at the highest income brackets and those at the bottom had significantly different trip temporal distributions those at the middle had similar ones. For this reason, the trip temporal distributions shown in Figure 3 are shown in thin lines for the income brackets in the middle and thick lines for those at the top and bottom income brackets. While individuals with higher incomes had a more defined trip temporal distribution with two peaks, one for the morning and another for the afternoon, individuals with lower incomes tend to travel over the entire span of the day with their trip peaking around 15:00 hours. 


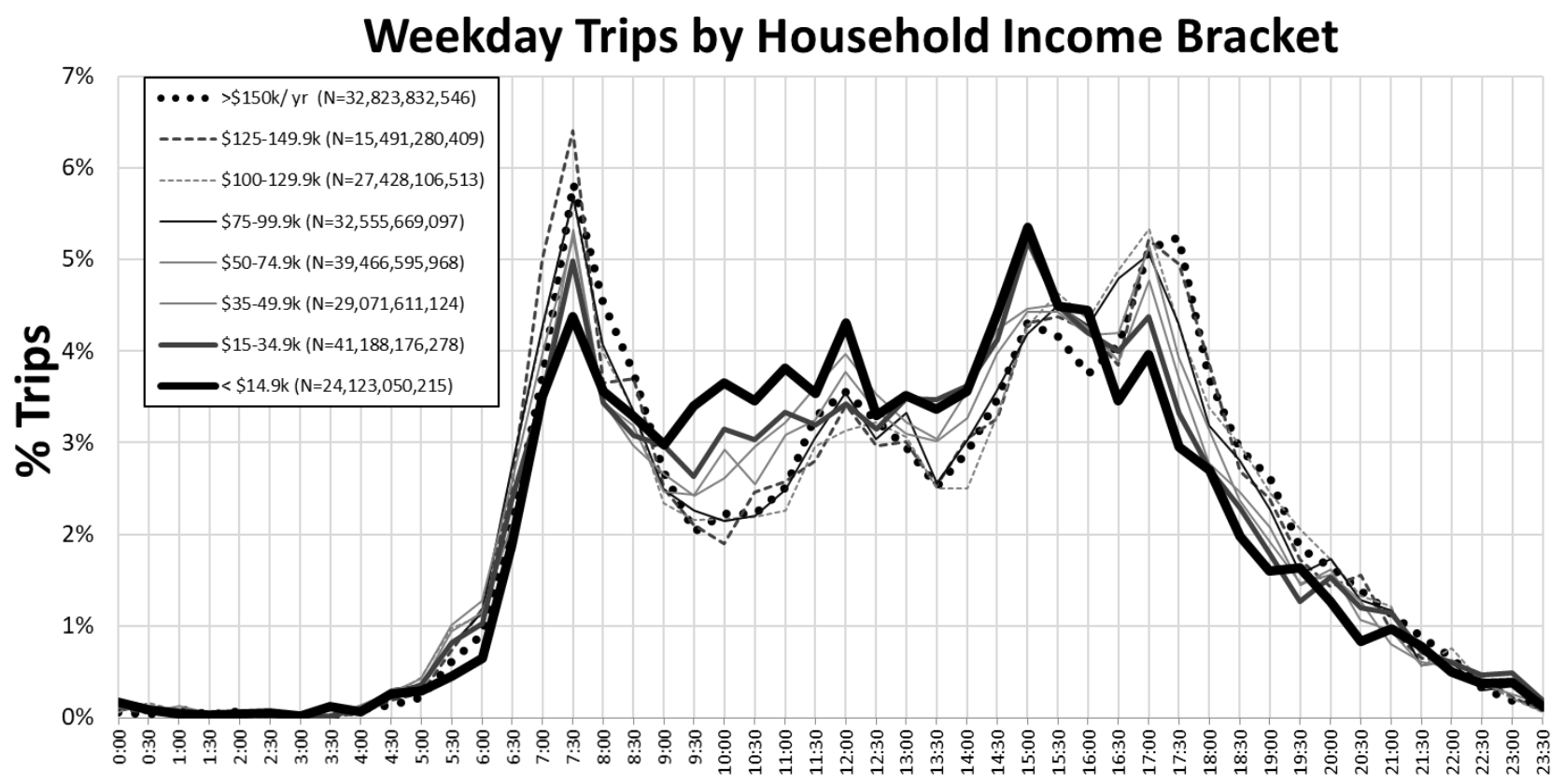

Figure 3: Temporal Distributions by Household Income

Table 17: Odds of travel on different time-of-day periods by household income

\begin{tabular}{|l|c|c|c|c|c|c|c|c|c|c|}
\hline & $\begin{array}{c}\text { Early } \\
\text { Morning }\end{array}$ & Morning & $\begin{array}{c}\text { Peak } \\
\text { Morning }\end{array}$ & $\begin{array}{c}\text { Late } \\
\text { Morning }\end{array}$ & $\begin{array}{c}\text { Mid- } \\
\text { day }\end{array}$ & Afternoon & $\begin{array}{c}\text { Peak } \\
\text { Afternoon }\end{array}$ & Evening & Night \\
\hline$>$ \$150,000 & \multicolumn{7}{|c|}{ Baseline } \\
\hline$\$ 125,000-\$ 149,999$ & 1.036 & $\mathbf{1 . 1 4 8}$ & $\mathbf{0 . 9 6 2}$ & 0.986 & $\mathbf{0 . 9 9 8}$ & 1.010 & $\mathbf{1 . 0 3 7}$ & $\mathbf{0 . 9 5 4}$ & 0.696 \\
\hline$\$ 100,000-\$ 124,999$ & $\mathbf{1 . 4 8 7}$ & $\mathbf{1 . 3 0 6}$ & $\mathbf{0 . 9 4 6}$ & 1.020 & 0.970 & 1.018 & $\mathbf{1 . 0 4 8}$ & $\mathbf{0 . 9 0 4}$ & 0.946 \\
\hline$\$ 75,000-\$ 99,999$ & $\mathbf{1 . 6 0 7}$ & $\mathbf{1 . 3 1 3}$ & $\mathbf{0 . 9 3 0}$ & 1.015 & 1.007 & $\mathbf{1 . 0 6 7}$ & $\mathbf{1 . 0 3 2}$ & $\mathbf{0 . 8 6 7}$ & 0.957 \\
\hline$\$ 50,000-\$ 74,999$ & $\mathbf{1 . 7 4 2}$ & $\mathbf{1 . 4 0 9}$ & $\mathbf{0 . 9 0 2}$ & $\mathbf{1 . 0 5 1}$ & 1.005 & $\mathbf{1 . 1 0 5}$ & 1.009 & $\mathbf{0 . 8 4 3}$ & 0.978 \\
\hline$\$ 35,000-\$ 49,999$ & $\mathbf{2 . 2 0 7}$ & $\mathbf{1 . 4 0 1}$ & $\mathbf{0 . 9 0 3}$ & $\mathbf{1 . 1 2 8}$ & 1.001 & $\mathbf{1 . 1 2 7}$ & 0.983 & $\mathbf{0 . 7 9 1}$ & 0.950 \\
\hline$\$ 15,000-\$ 34,999$ & $\mathbf{2 . 0 7 4}$ & $\mathbf{1 . 3 8 2}$ & $\mathbf{0 . 8 8 3}$ & $\mathbf{1 . 2 4 9}$ & 1.009 & $\mathbf{1 . 1 6 1}$ & $\mathbf{0 . 9 3 1}$ & $\mathbf{0 . 7 1 5}$ & 1.048 \\
\hline$<\$ 14,999$ & $\mathbf{2 . 0 4 2}$ & $\mathbf{1 . 1 8 0}$ & $\mathbf{0 . 9 0 1}$ & $\mathbf{1 . 4 6 1}$ & $\mathbf{1 . 0 9 9}$ & $\mathbf{1 . 2 5 6}$ & $\mathbf{0 . 8 3 6}$ & $\mathbf{0 . 6 0 5}$ & 0.962 \\
\hline
\end{tabular}

Bold lettering denotes that the variable is significant

The trip odds obtained from the binary logit regressions, shown in Table 17, provided some additional clarity to the information obtained in the trip temporal distribution plots. Besides providing definitive evidence that lower income individuals are more likely to travel in the early morning, and morning periods and less likely to travel during the evening than people belonging to the higher income bracket it is difficult to other draw conclusions due to the high p-values or low significance levels of numerous of the variables at different times of the day. 
Findings by Age

This analysis shows us the trip temporal distributions of trip makers that are at different stages of life.

While school age and middle age trip makers follow a weekday trip temporal distribution with two defined peaks, one in the morning and another in the afternoon, older adults are travelling more during the middle. Figure 4 shows these temporal distributions. Despite the large morning peak, the odds obtained via binary logit regressions show that trip makers under the age of 18 are the most likely to travel in the afternoon and peak afternoon when compared to our baseline of adults between the ages of 30 and 50 . Table 18 shows these odds.

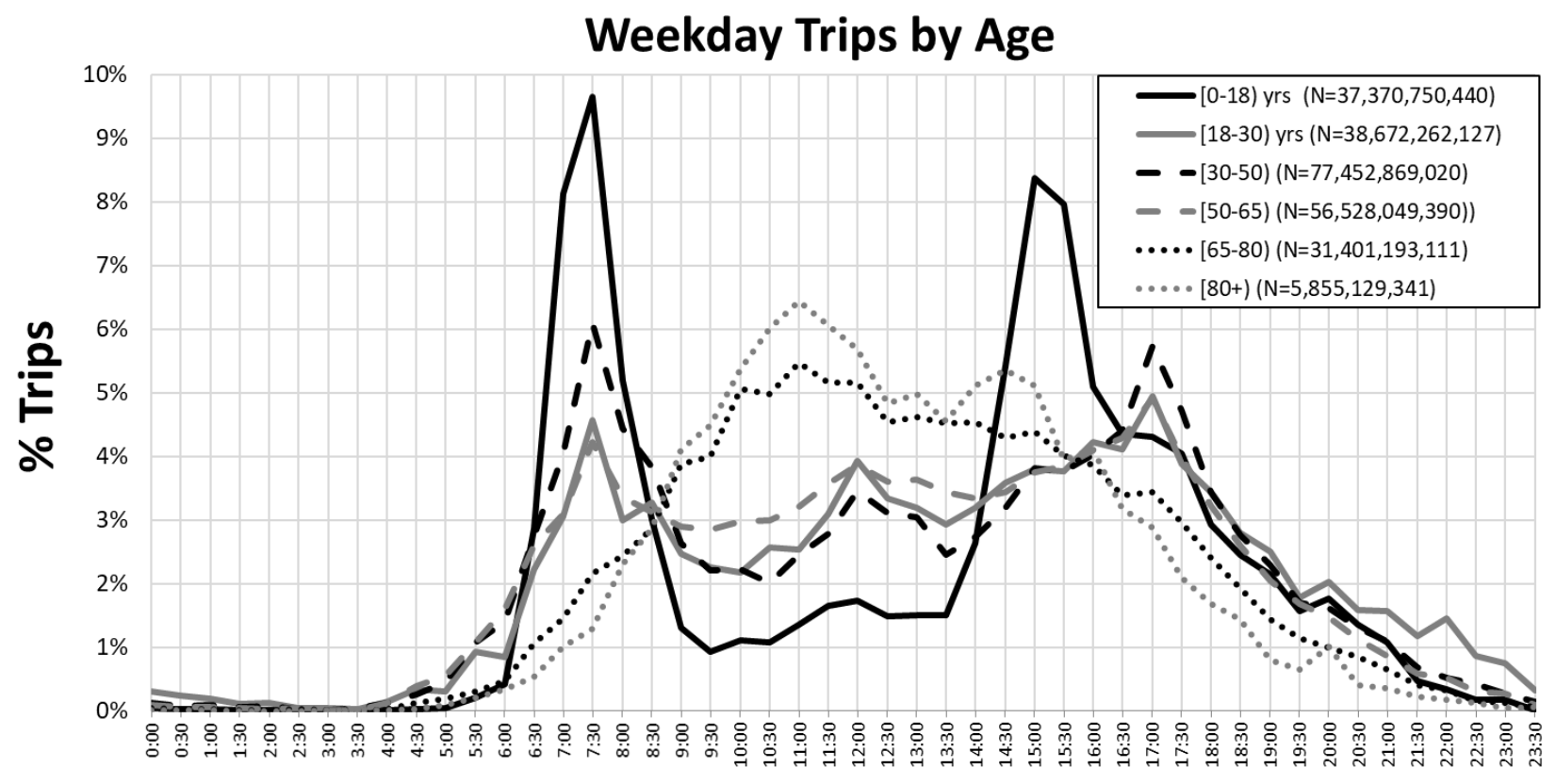

Figure 4: Temporal Distributions by age bracket

Table 18: Odds of travel on different time-of-day periods by age bracket

\begin{tabular}{|c|c|c|c|c|c|c|c|c|c|}
\hline & $\begin{array}{c}\text { Early } \\
\text { Morning }\end{array}$ & Morning & $\begin{array}{c}\text { Peak } \\
\text { Morning }\end{array}$ & $\begin{array}{c}\text { Late } \\
\text { Morning }\end{array}$ & $\begin{array}{l}\text { Mid- } \\
\text { day }\end{array}$ & Afternoon & $\begin{array}{c}\text { Peak } \\
\text { Afternoon }\end{array}$ & Evening & Night \\
\hline$[30-50)$ & \multicolumn{9}{|c|}{ Baseline } \\
\hline$[0-18)$ & 0.268 & 0.649 & 0.964 & 0.537 & 0.613 & 1.381 & 1.523 & 0.943 & 0.700 \\
\hline$[18-30)$ & 2.248 & 0.836 & 0.651 & 0.954 & 1.004 & 1.169 & 1.000 & 1.099 & 1.785 \\
\hline [50-65) & 0.710 & 1.181 & 0.834 & 1.271 & 1.130 & 1.285 & 0.906 & 0.791 & 0.809 \\
\hline [65-80) & 0.212 & 0.672 & 0.863 & 1.978 & 1.452 & 1.663 & 0.667 & 0.479 & 0.474 \\
\hline$[80+)$ & 0.070 & 0.522 & 0.920 & 2.294 & 1.610 & 1.747 & 0.573 & 0.361 & 0.297 \\
\hline
\end{tabular}

Bold lettering denotes that the variable is significant 


\section{Findings by transportation mode}

This analysis show that trip makers make use of different components of the transportation system at different times. While transit usage tends to concentrate mostly in the morning and afternoon with diminished usage in between, walking trips flourish during these hours especially near or at noon. Biking trips obey clear commuting trip trends with sharp peaks in the morning and afternoon rush hours and motor-vehicle trips are disperse throughout the day. Notably, both walking and motor-vehicle trips seem to peak around 15:00 hours. Figure 5 shows the trip temporal distributions, note that his plot does not include trips done on the school bus, this is because trips done at this time are so concentrated on the before and after school times the peaks of the temporal distributions of these trips were so high they distorted the plot making it difficult to observe the trip temporal distributions for other modes.

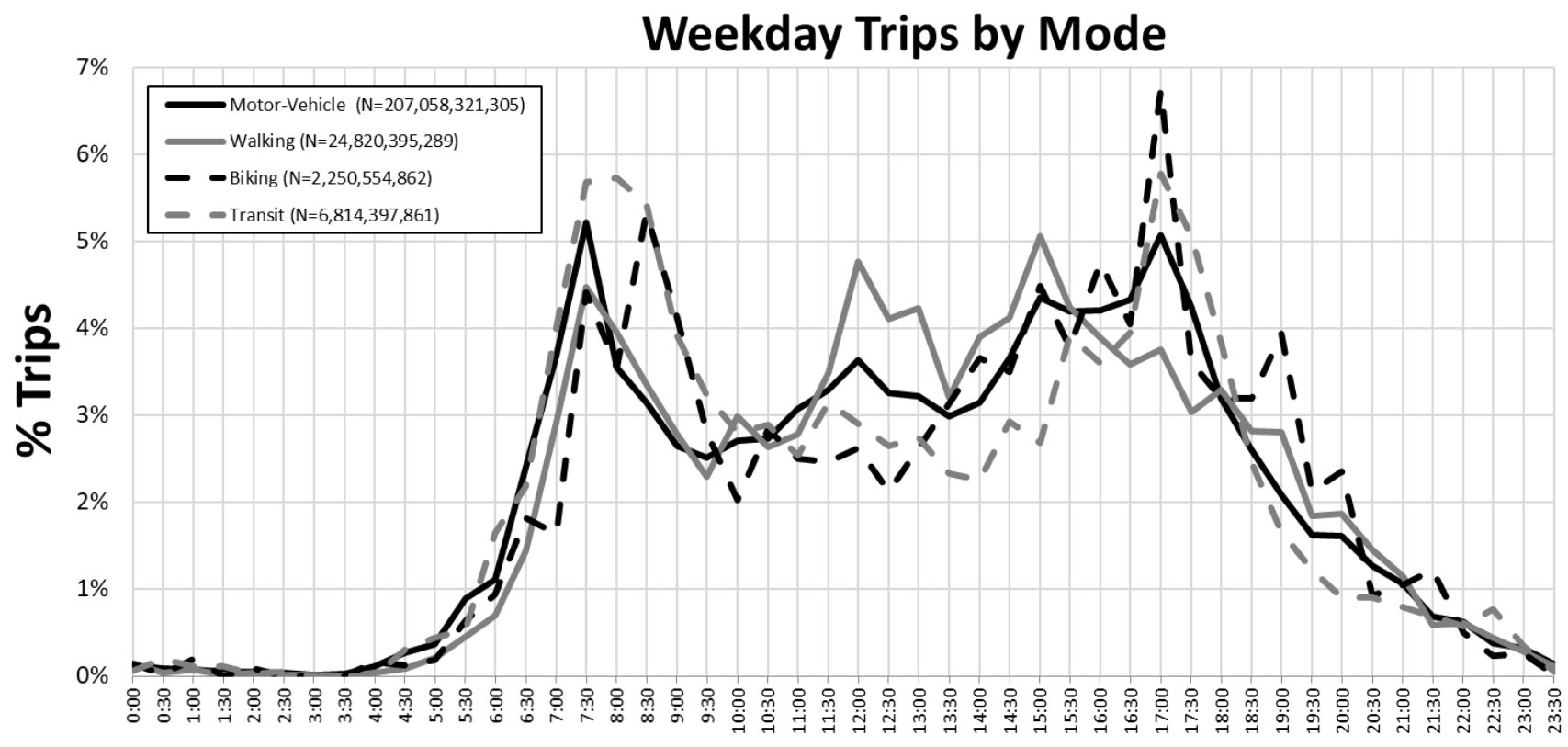

Figure 5: Temporal Distributions by transportation mode

The trip odds, shown in Table 19, by mode of transportation did not show anything remarkable but it is included for completion. 
Table 19: Odds of travel on different time-of-day periods by mode of transportation

\begin{tabular}{|l|c|c|c|c|c|c|c|c|c|c|c|}
\hline & $\begin{array}{c}\text { Early } \\
\text { Morning }\end{array}$ & Morning & $\begin{array}{c}\text { Peak } \\
\text { Morning }\end{array}$ & $\begin{array}{c}\text { Late } \\
\text { Morning }\end{array}$ & $\begin{array}{c}\text { Mid- } \\
\text { day }\end{array}$ & Afternoon & $\begin{array}{c}\text { Peak } \\
\text { Afternoon }\end{array}$ & Evening & Night \\
\hline Motor-Vehicle & \multicolumn{7}{|c|}{ Baseline } \\
\hline Walk & $\mathbf{0 . 6 6 6}$ & $\mathbf{0 . 8 9 5}$ & $\mathbf{1 . 0 5 7}$ & $\mathbf{1 . 1 0 6}$ & $\mathbf{1 . 2 7 1}$ & $\mathbf{1 . 0 5 2}$ & $\mathbf{0 . 7 5 5}$ & $\mathbf{1 . 0 9 2}$ & 0.965 \\
\hline Bike & $\mathbf{0 . 4 4 1}$ & $\mathbf{0 . 7 2 9}$ & 1.030 & $\mathbf{1 . 3 9 2}$ & 0.971 & 1.063 & $\mathbf{0 . 9 0 4}$ & 0.964 & $\mathbf{0 . 7 0 7}$ \\
\hline Transit & $\mathbf{0 . 7 3 5}$ & $\mathbf{0 . 8 9 0}$ & $\mathbf{1 . 3 2 6}$ & $\mathbf{1 . 1 1 2}$ & $\mathbf{0 . 7 9 1}$ & $\mathbf{0 . 8 0 5}$ & $\mathbf{1 . 1 1 4}$ & 0.927 & $\mathbf{0 . 7 4 9}$ \\
\hline School Bus & -- & $\mathbf{1 . 5 8 7}$ & $\mathbf{1 . 1 5 4}$ & $\mathbf{0 . 2 8 5}$ & $\mathbf{0 . 2 5 7}$ & $\mathbf{2 . 5 2 4}$ & $\mathbf{1 . 9 3 6}$ & $\mathbf{0 . 0 3 0}$ & $\mathbf{0 . 0 3 6}$ \\
\hline
\end{tabular}

Bold lettering denotes that the variable is significant

\section{Findings by Trip Purpose}

The final category analyzed was trip purpose. This category was included because, as we are going to see in the next section, it can be used as an interaction term to describe the trip temporal distributions of very specific groups of people such as women that run errands after work or older adults that engage in social and recreation trips during the midday. In the interest of completion, we included both the plot showing the trip temporal distributions and the table showing the travel odds. As we can see from Figure 6, nothing out of the ordinary jumps out. Work trips occur towards the beginning of the day while return home trips occur towards the end of the day. Social, recreational, shopping and errand trips occur towards the middle of the day. The odds shown in Table 20 show these same trends. 


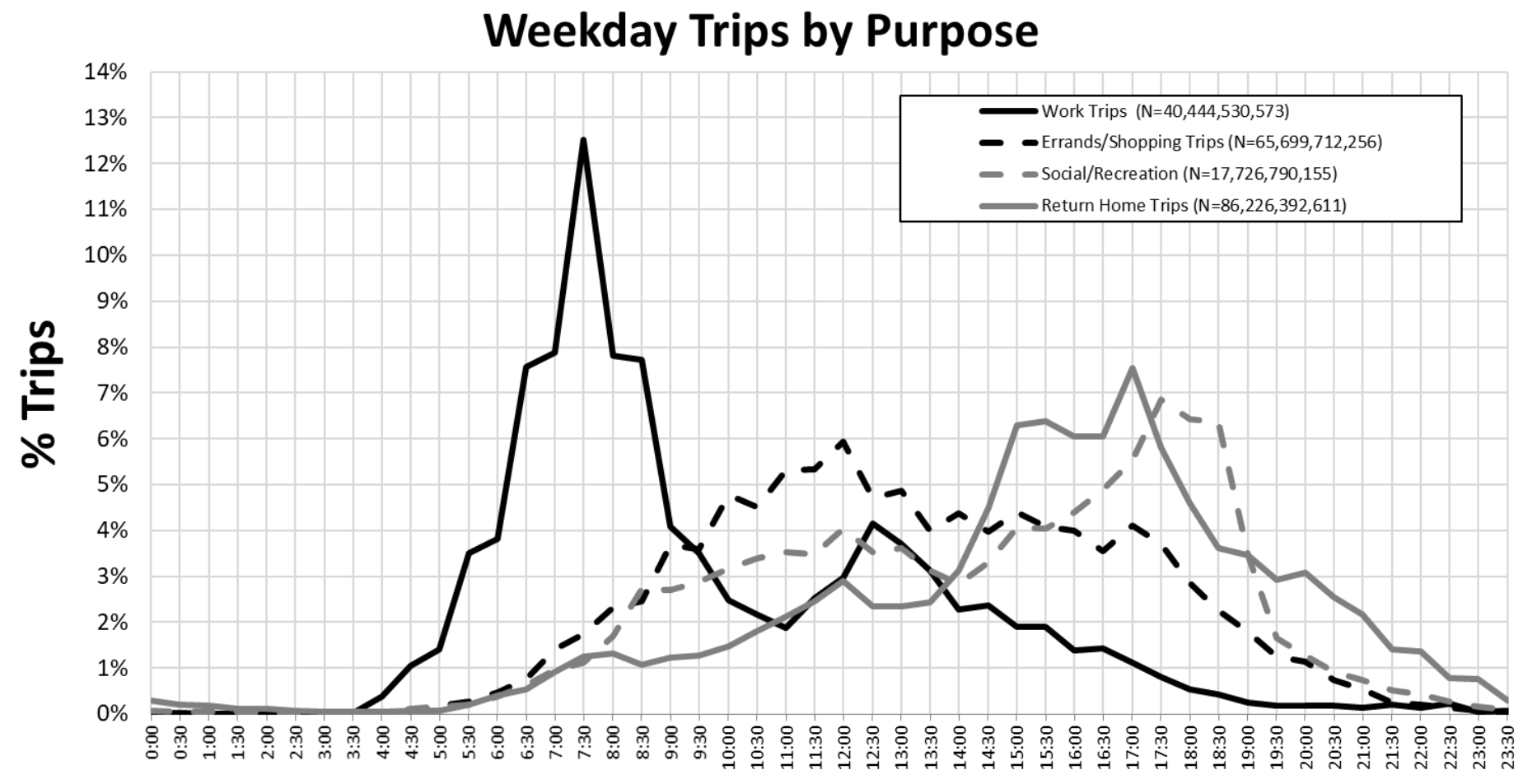

Figure 6: Temporal Distributions by trip purpose

Table 20: Odds of travel on different time-of-day periods by trip purpose

\begin{tabular}{|l|c|c|c|c|c|c|c|c|c|}
\hline & $\begin{array}{c}\text { Early } \\
\text { Morning }\end{array}$ & Morning & $\begin{array}{c}\text { Peak } \\
\text { Morning }\end{array}$ & $\begin{array}{c}\text { Late } \\
\text { Morning }\end{array}$ & $\begin{array}{c}\text { Mid- } \\
\text { day }\end{array}$ & Afternoon & $\begin{array}{c}\text { Peak } \\
\text { Afternoon }\end{array}$ & Evening & Night \\
\hline Work & \multicolumn{9}{|c|}{ Baseline } \\
\hline School & $\mathbf{0 . 1 1 3}$ & $\mathbf{0 . 5 0 9}$ & $\mathbf{4 . 7 9 7}$ & $\mathbf{0 . 9 1 9}$ & $\mathbf{0 . 4 4 6}$ & $\mathbf{0 . 1 4 5}$ & $\mathbf{0 . 2 8 1}$ & $\mathbf{0 . 7 4 1}$ & $\mathbf{0 . 1 3 4}$ \\
\hline Errands/ Shopping & 1.086 & $\mathbf{0 . 0 9 3}$ & $\mathbf{0 . 1 4 5}$ & $\mathbf{1 . 5 3 7}$ & $\mathbf{1 . 5 7 1}$ & $\mathbf{1 . 5 0 0}$ & $\mathbf{3 . 8 0 6}$ & $\mathbf{7 . 2 6 4}$ & $\mathbf{1 . 7 6 9}$ \\
\hline Social/ Recreation & $\mathbf{2 . 1 3 5}$ & $\mathbf{0 . 0 9 8}$ & $\mathbf{0 . 1 2 9}$ & $\mathbf{1 . 0 8 5}$ & 1.005 & $\mathbf{1 . 1 2 7}$ & $\mathbf{5 . 2 5 5}$ & $\mathbf{1 6 . 8 0 3}$ & $\mathbf{3 . 3 9 1}$ \\
\hline Return Home & $\mathbf{1 0 . 8 9 3}$ & $\mathbf{0 . 0 7 3}$ & $\mathbf{0 . 0 8 2}$ & $\mathbf{0 . 5 6 5}$ & $\mathbf{0 . 7 6 7}$ & $\mathbf{1 . 1 9 5}$ & $\mathbf{7 . 2 1 0}$ & $\mathbf{1 7 . 8 2 3}$ & $\mathbf{1 2 . 4 2 3}$ \\
\hline
\end{tabular}

Bold lettering denotes that the variable is significant 


\section{Equity Questions and Parameter Interactions}

Analysis

A few trends came up when reviewing the six trip temporal distributions presented above regarding the trip making habits of minorities, women, people with lower incomes, transit users, the elderly and the very young among others. These trends, combined with the literature, informed our future inquiries regarding the trip temporal distributions of more specific trip making groups. We wanted to look into specific groups that we felt, based on the information uncovered in the previous section as well as the literature review, may be particularly underserved by the current transportation status quo. Since an individual trip maker can belong to one or many of these categories it is reasonable to infer that these parameters may have an influence on one another, and in determining whether the trip maker engages with the transportation system at all. This interference between parameters and their variables is called an interaction and it is the basis of our next analysis.

Question 1: How does race and income impact the afternoon travel of underage trip makers?

The first thing that jumped out when looking at the literature is the fact that 15:00 hours is the most dangerous time-of-day for children. As we can see from Figure 4, this is may be due to the fact that there are many children on the road at this time perhaps because they are returning home from school. As described in the literature, underage trip makers, African-American, American Indians, and Hispanic trip makers as well as trip makers that either walk or bike to their destinations are especially vulnerable road users. For this reason, we decided to further explore the interaction between race and mode of transportation for a subset of trips taken by people under the age of 18 for the time-of-day periods between 13:30 to 15:00 hours and between 15:00 and 18:00 hrs. Our results are presented in Table 21. We could have created a new plot showing the temporal distribution of these very specific groups with plots but these look very similar for certain groups so it is hard to learn much from them. For this reason, we chose to rely on the odds obtained from binary logit regression models as they can provide more definitive and quantitative answers. 
Table 21: Odds of travel during afternoon hours for children under 18

\begin{tabular}{|l|c|c|}
\hline \multicolumn{1}{|c|}{ Nagelkerke R $^{2}$} & 0.013 & 0.02 \\
\hline \multicolumn{1}{|c|}{ Gosmer and Lemeshow Significance } & $>0.99$ & $>0.99$ \\
\hline Non-Hispanic White & Afternoon & $\begin{array}{c}\text { Peak } \\
\text { Afternoon }\end{array}$ \\
\hline Hispanic any race & \multicolumn{2}{|c|}{ Baseline } \\
\hline African-American & 0.942 & $\mathbf{0 . 9 3 0}$ \\
\hline Asian & 0.938 & $\mathbf{0 . 9 6 4}$ \\
\hline American Indian & $\mathbf{1 . 1 7 2}$ & $\mathbf{0 . 9 3 3}$ \\
\hline Pacific Islander & 1.133 & $\mathbf{0 . 7 2 2}$ \\
\hline Motor-Vehicle & 1.669 & $\mathbf{0 . 7 5 0}$ \\
\hline Walk & \multicolumn{2}{c|}{ Baseline } \\
\hline Bike & $\mathbf{1 . 7 5 7}$ & $\mathbf{1 . 1 7 8}$ \\
\hline Transit & $\mathbf{1 . 8 4 6}$ & $\mathbf{1 . 1 1 0}$ \\
\hline School Bus & $\mathbf{1 . 6 5 2}$ & $\mathbf{1 . 0 2 1}$ \\
\hline Non-Hispanic White \& Motor-Vehicle & $\mathbf{1 . 8 0 3}$ & $\mathbf{1 . 0 3 9}$ \\
\hline Bike - Hispanics & 0.565 & --- \\
\hline Bike - Asian & 0.438 & --- \\
\hline Walk - African American & --- & $\mathbf{1 . 2 2 2}$ \\
\hline Walk - American Indian & --- & $\mathbf{2 . 1 8 9}$ \\
\hline
\end{tabular}

Bold lettering denotes that the variable is significant

A few things jump point when reviewing Table 21. Regrettably, when it comes to the race-ethnicity parameter on its own none of the variables except the one for Asian-Americans are significant enough. According to our literature review Asian-Americans have the lowest likelihood of dying while walking and no red flags regarding their safety on the road came up. For this reason, we will not concentrate in this result. The next parameter analyzed was transportation mode, here every variable in both the Afternoon and Peak Afternoon models was significant. We learned that, in the case of under age children walking, biking, taking public transportation and the school bus are stronger predictors of afternoon travel than using a motor-vehicle. These results underscore the vulnerability of underage trip makers during this time-of-day period. Not only are children more likely to travel during the afternoon as shown in Figure 4, but they are likely to do so in modes of transportation that make them vulnerable to motor-vehicles such as biking and walking.

The variable interactions told an important story too. Two variables that came close to the significance threshold were Bike-Hispanic and Bike-Asian. These variables tell us that Hispanic and Asian children are the likeliest to engage in a bike trip during the afternoon hours from 13:30 to 15:00. Additionally, we learned that African-Americans and American Indian children are by far the more likely to engage in walking trips between the hours of 15:00 and 18:00 than any other group. According to the literature, these two racial-ethnic groups have the highest fatality and injury rates for pedestrians which means these child populations are at risk too. 
Transportation professionals and public officials should keep this in mind when implementing temporal based safety enhancements around children such as those related to walking school buses, adult crossing guards, dynamic speed limits, and in some cases traffic signal timing to allow for additional crossing time among numerous other safety enhancing treatments. Informed by our results shown in Table $X$ and in the interest of equity, we can say that African-American and American Indian populations should be prioritized when the treatment enhances pedestrian safety and Hispanic populations should be prioritized when the treatment enhanced biking safety since they are the most exposed to the dangers of the road.

Question 2: Do race and income play a role in determining whether someone travels early in the morning and what transportation mode they use?

This time period corresponds to what we call early morning and morning trips. As mentioned in the introduction, this is a relatively dangerous time-of-day for all road users because of the lack of natural lighting and a time-of day in which transit dependent populations are the least able to access transit options. For this reason, we wanted to look at the likelihood trip makers, with a household income of $\$ 49,999$ or less, are of making a trip during this time period based on their race, income and mode choice. Our results are displayed on Table 22.

As we can see from Table 21, we ran two models. One called Early Morning model which captures all trips occurring from 00:00 to 04:00 and one called Morning model which captures all trips occurring between 04:00 and 07:00. The Early Morning model shows that African-Americans and Pacific Islanders are significantly more likely to engage in a trip at this time-of-day than non-Hispanic whites. Recall that our literature review uncovered the fact that these two groups are disproportionally killed when using the transportation system. We believe that there may be a connection between these groups being disproportionally killed when using the road and the fact that they have to use it when is dark outside. However, testing this connection is outside the scope of this project. Unfortunately, we couldn't uncover much more since our interaction terms between the race-ethnicity parameter and the income and transportation mode parameters did not yield odds with a significance level or p-value under the 0.05 threshold. The Morning model was more successful in showing more results with an acceptable significance level. We uncovered that Hispanics and African-Americans with a household income of $\$ 49,999$ a year or less are $53 \%$ and $27 \%$ more likely to travel during this time period than non-Hispanic whites with the same income level. We also showed that African-Americans and Hispanics with an annual household income between $\$ 15,000$ and 34,999 are the most likely to be using the transportation system during the morning. Finally, we found that although the odds of Hispanic and African-American 
trip makers to engage in a walking trip are only about half the size than the odds of a non-Hispanic white to drive during the morning period. These are high odds that speak to the additional roadway exposure these groups are exposed to decreasing the safety outcomes when engaging with the transportation system.

These results speak to the unique ways different groups engage with the transportation system during the first few hours of every day. Transportation professionals and public officials ought to consider these differences in trip temporal distributions when weighing decisions such as where to locate additional public lighting or funding for sidewalks and high-visibility crosswalks. It is clear that groups such as Pacific Islanders, African-Americans and Hispanics would benefit the most from these upgrades since they travel the most when is dark and are the most exposed to the dangers of the road.

Table 22: Odds of travel during afternoon hours for children under 18

\begin{tabular}{|l|c|c|}
\hline \multicolumn{1}{|c|}{ Nagelkerke R ${ }^{2}$} & 0.07 & 0.05 \\
\hline \multicolumn{1}{|c|}{ Group Analyzed } & 0.354 & 0.013 \\
\hline Non-Hispanic White & $\begin{array}{c}\text { Early } \\
\text { Morning }\end{array}$ & Morning \\
\hline Hispanic any race & \multicolumn{2}{c|}{ Baseline } \\
\hline African-American & 1.346 & $\mathbf{1 . 5 3 4}$ \\
\hline Asian & $\mathbf{3 . 4 9 0}$ & $\mathbf{1 . 2 7 3}$ \\
\hline American Indian & 1.607 & 0.933 \\
\hline Pacific Islander & --- & 0.637 \\
\hline \$35,000 - \$49,999 & 5.992 & 0.807 \\
\hline \$15,000 - \$34,999 & \multicolumn{2}{c|}{ Baseline } \\
\hline$<$ \$14,999 & 0.995 & 0.765 \\
\hline Motor-Vehicle & 1.124 & 0.580 \\
\hline Walk & \multicolumn{2}{c|}{ Baseline } \\
\hline Bike & 1.154 & 0.976 \\
\hline Transit & 1.768 & 1.007 \\
\hline Non-Hispanic White - \$35,000 - \$49,999 & \multicolumn{2}{|c|}{ Baseline } \\
\hline African-American - \$15,000 - \$34,999 & $\mathbf{0 . 5 2 6}$ & $\mathbf{1 . 3 0 2}$ \\
\hline Hispanic - \$15,000 - \$34,999 & 1.123 & $\mathbf{1 . 3 4 0}$ \\
\hline Non-Hispanic White - Motor-Vehicle & \multicolumn{2}{|c|}{ Baseline } \\
\hline Hispanic - Walk & 1.013 & $\mathbf{0 . 5 1 7}$ \\
\hline African American - Walk & 0.726 & $\mathbf{0 . 5 7 0}$ \\
\hline
\end{tabular}

Bold lettering denotes that the variable is significant 
Question 3: Is there a difference along gender lines on afternoon travel?

As we mentioned in the introduction, this question came about because the literature review pointed out the inequities in travel between women and men. The trip temporal distributions shown in Figure 2 and the trip odds shown in Table 15 served as a quick confirmation of these trends. Women do indeed have markedly different trip temporal distributions than men. Most notable of all, Figure 2 shows that female trip makers have a noticeably sharper trip temporal distribution peak around 3pm or 15:00 hours. Since the literature pointed out that women are more likely to engage in household related trips such as shopping and other household related errand trips sometime in the afternoon after they are done working, picking up children from school or both, we wanted to compare the odds of travel for female and male trip makers engaged in this type of trip and compare those odds to the odds of them engaging on a trip to simply return home during this time period which is another likely type of trip to occur during these time periods. Our results are shown in Tables 23 and 24.

Tables 23: Odds of return home travel in the afternoon and peak afternoon periods

\begin{tabular}{|l|c|c|}
\hline \multicolumn{1}{|c|}{$\begin{array}{c}\text { Nagelkerke } \mathrm{R}^{2} \\
\begin{array}{c}\text { Hosmer and Lemeshow } \\
\text { Significance }\end{array}\end{array}$} & 0.009 & 0.018 \\
\hline \multicolumn{1}{|c|}{ Group Analyzed } & Afternoon & Peak Afternoon \\
\hline Male & \multicolumn{2}{|c|}{ Baseline } \\
\hline Female & $\mathbf{1 . 1 7 5}$ & 0.984 \\
\hline Motor Vehicles & \multicolumn{2}{|c|}{ Baseline } \\
\hline Walk & $\mathbf{0 . 9 3 2}$ & $\mathbf{0 . 6 1 9}$ \\
\hline Bike & 1.086 & 0.933 \\
\hline Transit & 1.063 & $\mathbf{1 . 3 7 0}$ \\
\hline Male - Motor Vehicle & \multicolumn{2}{|c|}{ Baseline } \\
\hline Female - Walk & $\mathbf{0 . 8 3 8}$ & 1.013 \\
\hline Female - Bike & 0.843 & 0.951 \\
\hline Female - Transit & 0.867 & 1.039 \\
\hline
\end{tabular}

Bold lettering denotes that the variable is significant

Tables 24: Odds of shopping and errand travel in the afternoon and peak afternoon periods

\begin{tabular}{|l|c|c|}
\hline \multicolumn{1}{|c|}{${\text { Nagelkerke } \mathrm{R}^{2}}^{\text {Hosmer and Lemeshow }} \begin{array}{c}\text { Significance } \\
\text { Group Analyzed }\end{array}$} & 0.01 & 0.002 \\
\hline Male & Afternoon & Peak Afternoon \\
\hline Female & $\mathbf{2}$ \\
\hline Motor Vehicles & $\mathbf{1 . 1 5 7}$ & $\mathbf{1 . 0 8 1}$ \\
\hline Walk & 1.006 & $\mathbf{0 . 9 1 8}$ \\
\hline Bike & 1.066 & 1.164 \\
\hline Transit & $\mathbf{0 . 7 6 1}$ & $\mathbf{0 . 8 8 2}$ \\
\hline
\end{tabular}

Bold lettering denotes that the variable is significant 
As we can see from Tables 24, women are almost $16 \%$ and $8 \%$ more likely to engage in a shopping trip than men during the afternoon and peak afternoon periods a finding that speaks volumes about women's role as homemakers even in $21^{\text {st }}$ century US. We wanted to test the interaction between the gender and transportation mode parameters to find out more about how where women doing these shopping and errand trips, unfortunately none of the odds produced by the models were statistically significant.

Table 23 showed the odds of women engaging in a return home. These results too spoke about the different house roles women and men have. Women are almost $18 \%$ more likely than men to head home sometime in the afternoon period (13:30 to 15:00) presumably after working. Although we didn't explore this avenue, this may be an indication that they are more likely to have a part-time job instead of a fulltime a fact that may hinder their income and career prospects. We also found that have significantly high odds of walking on their return home trips, these odds being only about $16 \%$ lower than those of men to drive back home. Considering that the motor-vehicle is such a popular option the odds for women to walk home seem high.

These differences in travel are important because women seem to be travelling outside of what it is considered the evening rush hour by modes such as walking and with motivations and destinations different that those of men. This is important because only $13 \%$ of engineers in the United States are women (Society of Women Engineers, 2018) and, although the differences are not stark in the field of urban planning, engineers are often in charge of making transportation related decisions that impact everybody. Female trip maker's needs may be overlooked by these decision makers since decision makers may not be acquainted with the differences in trip temporal distribution and transportation needs that women have. We exhort transportation engineers and other decision makers to keep these differences in mind when making decisions such as the frequency and coverage of transit during the afternoon hours (when women are more likely to be engaged in return home trips or running errands).

\section{Question 4: How do adults over the age of 65 differ in their nighttime and early morning travel along} race lines?

This was the last question analyzed. The question deals with the vulnerable population that is constituted of adults over the age of 65 and compares the odds of them travelling during nighttime hours based on their race and ethnicity, and their mode of transportation regardless of whether they prefer to use said mode or they have no other option due to economic or age-related constraints. Our results are presented in Table 25. As we can see from the top half of this table, the race-ethnicity parameter has an important impact on the nighttime trip temporal distributions of older adults. We observed that, with the exception of Hispanics, all minority groups are more likely to engage in nighttime travel than non-Hispanic whites. 
This is an important finding because older minority adults are at an especially high risk. Not only, as mentioned in the literature, are they more likely due to their race to be experiencing poverty, to be transitdependent, to walk to their destinations and to live in areas in which roads are dangerous walking but also, due to their advance age, to have decreased mobility, hearing, and sight and therefore be more when vulnerable when attempting basic tasks such as crossing a busy roadway by feet. Finally, the second half of the table speaks to the transportation mode choices and access of older adults regardless of their race. As we can see walking and taking transit, a mode that relies on walking to get to and from the stop or transit station, are overwhelmingly popular with older adults. This also speaks to their vulnerability. The literature confirms this, pedestrians over the age of 65 are $198 \%$ more likely to be killed for every persontrip they take (Beck, 2017)

Table 25: Odds of travel for adults over 65 based on race and mode of

\begin{tabular}{|l|c|c|c|}
\hline \multicolumn{1}{|c|}{$\begin{array}{c}\text { Nagelkerke } \mathrm{R}^{2} \\
\begin{array}{c}\text { Hosmer and Lemeshow } \\
\text { Significance }\end{array}\end{array}$} & 0.003 & 0.04 & 0.09 \\
\hline \multicolumn{1}{|c|}{$\begin{array}{c}\text { Group Analyzed } \\
\text { Non-Hispanic White }\end{array}$} & Night & Early Morning & Morning \\
\hline Hispanic any race & 1.116 & 1.014 & $\mathbf{1 . 1 8 7}$ \\
\hline African-American & $\mathbf{1 . 2 7 4}$ & $\mathbf{1 . 9 0 8}$ & 1.118 \\
\hline Asian & $\mathbf{1 . 6 0 8}$ & $\mathbf{2 . 2 3 5}$ & 1.211 \\
\hline American Indian & $\mathbf{1 . 8 4 8}$ & 2.113 & 1.197 \\
\hline Motor-Vehicle & & Baseline & \\
\hline Walk & $\mathbf{1 . 4 7 6}$ & 0.816 & $\mathbf{2 . 2 9 8}$ \\
\hline Bike & $\mathbf{0 . 2 0 8}$ & --- & 1.543 \\
\hline Transit & 1.188 & 1.784 & $\mathbf{1 . 5 4 0}$ \\
\hline
\end{tabular}

Bold lettering denotes that the variable is significant

\subsection{CONCLUSION}

The results presented above gave us a glimpse of the complicated relationship between human trip makers and their transportation choices. We found several relationships between the socio-demographic characteristics of trip makers, their trip temporal distributions and their transportation mode choices. We found differences along gender, racial, income, and age lines that make trip makers such as minorities, women, those with lower incomes, children and older adults vulnerable when using a transportation system that theoretically should be accessible to all but in practice is exclusionary and unsafe. It is our sincerest wish that our findings are the eyes of those in positions of power to the wider array of trip makers that make use of the transportation systems under their leadership. 


\subsection{REFERENCES}

\section{Dataset}

Federal Highway Administration. (2017). 2017 National Household Travel Survey, U.S. Department of Transportation, Washington, DC. Available online: https://nhts.ornl.gov.

Academic Papers

Allen-Munley, C., Daniel, J,. \& Dhar, S. (2004). Logistic Model for Rating Urban Bicycle Route Safety. Transportation Research Record, (1878), 107-115.

Beck, L., Dellinger, A., \& O’Neil, M. (2007). Motor Vehicle Crash Injury Rates by Mode of Travel, United States: Using Exposure-Based Methods to Quantify Differences. American Journal of Epidemiology, 166(2), 212-218.

Clifton, K., \& Levi, A. (2004). Gender Differences in Walking Behavior, Attitudes About Walking, and Perceptions of the Environment in Three Maryland Communities. Research on Women's Issues in Transportation, 2(35), 79-88.

Coughenour, C., Clark, S., Singh, A., Claw, E., Abelar, J ., \& Huebner, J. (2016). Examining racial bias as a potential factor in pedestrian crashes. Accident Analysis and Prevention, 98(2017), 96-100.

Collins, D., \& Tisdell, C. (2002). Gender and Differences in Travel Life Cycles. Journal of Travel Research, 41, 133-143.

Dill, J., Goddard, T., Monsere, C., \& McNeil, N. (2014). Can Protected Bike Lanes Help Close the Gender Gap in Cycling? Lessons from Five Cities. Urban Studies and Planning Faculty Publications and Presentations, 123.

Emond, C., Tang,W., \& Handy, S. (2009). Explaining Gender Difference in Bicycling Behavior. Transportation Research Record, (2125), 16-25.

Garrard, J., Rose,R., \& Kai Lo, S. (2007). Promoting transportation cycling for women: The role of bicycle infastructure. Preventive Medicine, (46), 55-59.

Garrard, J., Handy, S., \& Dill, J. (2012). Women in Cycling. In Puchner, J., \& Buehler, R (Eds.) City Cycling. (pg. 211-234). MIT Press.

Garret, M., \& Taylor, B. (1999). Reconsidering Social Equity in Public Transit. Berkeley Planning Journal 13(1), 6-67. 
Goddard, T., Bersamian Kahn, K., \& Adkins, A. (2015). Racial bias in driver yielding behavior at crosswalk. Transportation Research Part F, 33(2015), 1-6.

Giuliano, G. (2003). Travel, location and race/ethnicity. Transportation Research: Part A, (37), 351-372.

Horner, M., \& Mefford, J. (2007). Investigating urban spatial mismatch using job-housing indicators to model home-work separation. Environment and Planning A, (39), 1420-1440.

Jiao, J., \& Dillivan, M. (2013). Transit Deserts: The Gap between Demand and Supply. Journal of Public Transportation, 3(16), 23-39.

McGuckin, \& Murakami, E. (1999). Examining Trip-Chaining Behavior: Comparison of Travel by Men and Women. Transportation Research Record, 1(1693), 79-85.

McGuckin, N., \& Nakamoto, Y. (2005). Differences in Trip Chaining by Men and Women. Transportation Research Record, 2(35), 49-56.

Morency, P., Gauvin, L., Plante, C., Fournier, M., \& Morency, C. (2012). Neighborhood Social Inequalities in Road Traffic Injuries: The Influence of Traffic Volume and Road Design. American Journal of Public Health, 102(6), 1112-1119.

Murakami, E., \& Young, J. (1997). Daily Travel by Persons with Low Income. NPTS Symposium. Betheda, MD. October 29-31.

Nambisan, S., Pulugurtha, S., Vasudevan, V., Dangeti, M., \& Virupaksha, V. Effectiveness of Autmatic Pedestrian Detection Device and Smart Lighting for Pedestrian Safety. Transportation Research Record, 2140, 27-34.

Schieber, RA., \& Vegega, ME. (2002). Reducing Childhood pedestrian injuries. Injury Prevention, 8, i3i8.

Singleton, P., \& Goddard, T. (2016). Cycling by Choice or Necessity? Exploring the Gender Gap in Bicycling in Oregon. Transportation Research Record, (2598), 110-118.

Stevenson, M., Sleet, D., \& Feguson R. (2015). Preventing Child Pedestrian Injury: A Guide for Practitioners. Am J Liefestyle M. 9(16). 442-450.

Sze, N., Su, J., Bai, L. (2019). Exposure to pedestrian crash based on household survey data: Effect of trip purpose. Accident Analysis and Prevention, (128), 17-24.

Thomas, T., Jaarsma,R ., Tutert, B. (2012). Exploring temporal fluctuations of daily cycling demand on Dutch cycle paths: the influence of weather on cycling. Transportation. 40, 1-22. 
Toran Pour, A., Moridpour, S., Tay, R., Rajabifard, A. (2017). Influence of pedestrian age and gender on spatial and temporal distribution of pedestrian crashes. Traffic Injury Prevention. (19), 81-87

Vance C, R., \& Iovanna, R. (2007). Gender and the Automobile: Analysis of Nonwork Service Trips. Transportation Research Record, 2013, 54-61.

Wachs, M. (1987). Men, Women and Wheels: The Historical Basis of Sex Differences in Travel Patterns. Transportation Research Record, 1135, 10-16.

Yu, Chia-Yuan. (2014). Environmental supports for walking/biking and traffic safety: Income and ethnicity disparities. Preventive Medicine, 67, 12-16.

\section{Other sources}

Anderson, M. (2016). Who relies on public transit in the U.S. Pew Research Center. Retrieved from: https://www.pewresearch.org/fact-tank/2016/04/07/who-relies-on-public-transit-in-the-u-s/

American Automobile Association. (2019). Your Driving Costs. NewsRoom. Retrieved from:

https://newsroom.aaa.com/auto/your-driving-costs/

Bullard, R. (2004). Introduction. Bullard, D., Johnson, G., Torres, A. Highway Robbery: Transportation Racism \& New Routes To Equity. (pp. 1-14). South End Press

Center for Disease Control. (2008). Childhood Injury Report. Retrieved from: https://www.cdc.gov/safechild/pdf/CDC-ChildhoodInjury.pdf

Center for Disease Control. (2018). Safe Routes to School. Retrieved from:

https://www.cdc.gov/policy/hst/hi5/saferoutes/index.html

Clark, H. (2017). Who Rides Public Transportation. American Public Transportation Association.

Federal Highway Administration. (2012). FHWA Lighting Handbook. pg. 9

Goddard, T., Barsamian Kahn, K., Adkins, A. (2014). Racial Bias in Driver Yielding Behavior at Crosswalks. National Institute for Transportation and Communities.

Harrison, D. (August 22, 2019). Price of Good Economy: More Time Stuck in Traffic. The Wall Street Journal.

Hoffman, M. (2016). The Beginning of the Equity Era. Bike Lanes are White Lanes: Bicycle Advocacy and Urban Planner. (pp. 143-161). University of Nebraska Press. 
Hosmer, D., Lemeshow, S., Sturdivant, R. Applied Logistic Regression. $3^{\text {rd }}$ ed. Wiley, 2013.

National Highway Traffic Safety Association. (2018). Traffic Safety Facts - 2016 Data. Retrieved from: https://crashstats.nhtsa.dot.gov/Api/Public/ViewPublication/812493

Norton P. (2008). Traffic Safety for the Motor Age. Fighting Traffic: The Dawn of the Motor Age in the American City. (pp. 207-242). MIT Press.

Roberts, A., \& Ogunwole S. (October, 2018). The Population 65 Years and Older in the United States: 2016. American Community Survey Reports. Retrieved from:

https://www.census.gov/content/dam/Census/library/publications/2018/acs/ACS-38.pdf

Schmitt, A. (2020). Right of Way: Race, Class and the Silent Epidemic of Pedestrian Deaths in America. Island Press.

Smart Growth America. (2014). Dangerous by Design. Retrieved from:

https://smartgrowthamerica.org/dangerous-by-design/

Smart Growth America. (2019). Dangerous by Design. Retrieved from:

https://smartgrowthamerica.org/dangerous-by-design/ 


\section{APPENDIX A}

Binary Logistic Models for different weekday times of day.

\begin{tabular}{|c|c|c|c|c|c|c|c|c|c|}
\hline Group Analyzed & Early Morning & Morning & $\begin{array}{c}\text { Peak } \\
\text { Morning }\end{array}$ & $\begin{array}{c}\text { Late } \\
\text { Morning }\end{array}$ & $\begin{array}{l}\text { Mid- } \\
\text { day }\end{array}$ & Afternoon & $\begin{array}{c}\text { Peak } \\
\text { Afternoon }\end{array}$ & Evening & Night \\
\hline Nagelkerke $\mathrm{R}^{2}$ & 0.136 & 0.212 & 0.289 & 0.086 & 0.049 & 0.027 & 0.124 & 0.135 & 0.130 \\
\hline $\begin{array}{c}\text { Hosmer and } \\
\text { Lemeshow Significance }\end{array}$ & 0.072 & 0.000 & 0.000 & 0.000 & 0.000 & 0.000 & 0.000 & 0.000 & 0.000 \\
\hline Non-Hispanic White & \multicolumn{9}{|c|}{ Baseline } \\
\hline Hispanic any race & $1.329 *$ & $1.248^{*}$ & $1.045^{*}$ & $0.908^{*}$ & $0.921^{*}$ & $0.937^{*}$ & $0.970^{*}$ & $1.110^{*}$ & $1.210^{*}$ \\
\hline African-American & $2.095^{*}$ & $1.249 *$ & $1.033 * *$ & $0.896^{*}$ & $0.915^{*}$ & 0.983 & $0.963 *$ & $1.125^{*}$ & $1.278^{*}$ \\
\hline Asian & 1.189 & $0.794 *$ & 1.030 & 1.024 & $0.924^{*}$ & 0.970 & $0.927^{*}$ & $1.221^{*}$ & $1.204^{*}$ \\
\hline American Indian & 1.216 & 1.129 & 1.089 & 1.069 & 0.928 & 1.015 & 0.933 & 1.002 & 1.057 \\
\hline Pacific Islander & 1.525 & 1.142 & $1.267 * *$ & 0.859 & $0.854^{* *}$ & 1.014 & 0.936 & 0.944 & $1.639 *$ \\
\hline Male & \multicolumn{9}{|c|}{ Baseline } \\
\hline Female & $0.520^{*}$ & $0.619 *$ & $1.144^{*}$ & 1.011* & $1.046^{*}$ & $1.120 *$ & $1.013^{* *}$ & $0.928^{*}$ & $0.834^{*}$ \\
\hline$>\$ 150,000$ & \multicolumn{9}{|c|}{ Baseline } \\
\hline$\$ 125,000-\$ 149,999$ & 1.036 & $1.148^{*}$ & $0.962 * *$ & 0.986 & 0.998 & 1.010 & $1.037^{* *}$ & $0.954 * *$ & 0.696 \\
\hline$\$ 100,000-\$ 124,999$ & $1.487^{*}$ & $1.306^{*}$ & $0.946^{*}$ & 1.020 & $0.970^{* *}$ & 1.018 & $1.048^{*}$ & $0.904^{*}$ & $0.946 * * *$ \\
\hline$\$ 75,000-\$ 99,999$ & $1.607^{*}$ & $1.313^{*}$ & $0.930 *$ & 1.015 & 1.007 & $1.067^{*}$ & $1.032^{*}$ & $0.867^{*}$ & 0.957 \\
\hline$\$ 50,000-\$ 74,999$ & $1.742^{*}$ & 1.409* & $0.902^{*}$ & $1.051^{*}$ & 1.005 & $1.105^{*}$ & 1.009 & $0.843^{*}$ & 0.978 \\
\hline$\$ 35,000-\$ 49,999$ & $2.207^{*}$ & 1.401* & 0.903* & $1.128^{*}$ & 1.001 & $1.127 *$ & 0.983 & $0.791^{*}$ & 0.950 \\
\hline$\$ 15,000-\$ 34,999$ & $2.074^{*}$ & $1.382^{*}$ & $0.883^{*}$ & $1.249^{*}$ & 1.009 & $1.161^{*}$ & $0.931 *$ & $0.715^{*}$ & 1.048 \\
\hline$<\$ 14,999$ & $2.042^{*}$ & $1.180^{*}$ & $0.901^{*}$ & $1.461^{*}$ & $1.099 *$ & $1.256^{*}$ & $0.836^{*}$ & $0.605^{*}$ & 0.962 \\
\hline Motor-Vehicle & \multicolumn{9}{|c|}{ Baseline } \\
\hline Walk & $0.666^{*}$ & $0.895^{*}$ & $1.057^{*}$ & $1.106^{*}$ & $1.271^{*}$ & $1.052 *$ & $0.755^{*}$ & $1.092 *$ & 0.965 \\
\hline Bike & $0.441^{* * *}$ & $0.729 *$ & 1.030 & $1.392^{*}$ & 0.971 & 1.063 & $0.904^{*}$ & 0.964 & $0.707^{*}$ \\
\hline Transit & 0.735 & $0.890 * *$ & $1.326^{*}$ & $1.112^{*}$ & $0.791^{*}$ & $0.805^{*}$ & $1.114^{*}$ & $0.927^{* *}$ & $0.749 *$ \\
\hline School Bus & --- & $1.587^{*}$ & $1.154^{*}$ & $0.285^{*}$ & $0.257^{*}$ & $2.524 *$ & $1.936^{*}$ & $0.030 *$ & $0.036^{*}$ \\
\hline Work & \multicolumn{9}{|c|}{ Baseline } \\
\hline School & $0.113^{* *}$ & $0.509 *$ & 4.797* & $0.919 * *$ & $0.446^{*}$ & $0.145^{*}$ & $0.281^{*}$ & $0.741^{*}$ & $0.134^{*}$ \\
\hline Errands/Shopping & 1.086 & $0.093^{*}$ & $0.145^{*}$ & $1.537^{*}$ & $1.571^{*}$ & $1.500^{*}$ & $3.806^{*}$ & $7.264^{*}$ & $1.769^{*}$ \\
\hline Social/ Recreation & $2.135^{*}$ & 0.098* & $0.129 *$ & $1.085^{*}$ & 1.005 & $1.127^{*}$ & $5.255^{*}$ & $16.803^{*}$ & 3.391* \\
\hline Return Home & $10.893^{*}$ & $0.073^{*}$ & $0.082^{*}$ & $0.565^{*}$ & $0.767^{*}$ & $1.195^{*}$ & $7.210^{*}$ & $17.823^{*}$ & $12.423^{*}$ \\
\hline$[30-50)$ & \multicolumn{9}{|c|}{ Baseline } \\
\hline$[0-18)$ & $0.268 *$ & $0.649 *$ & 0.964 & $0.537 *$ & $0.613^{*}$ & $1.381^{*}$ & $1.523 *$ & $0.943 *$ & $0.700 *$ \\
\hline$[18-30)$ & $2.248^{*}$ & $0.836^{*}$ & 0.651 & $0.954^{*}$ & 1.004 & $1.169 *$ & 1.000 & $1.099 *$ & $1.785^{*}$ \\
\hline$[50-65)$ & $0.710^{*}$ & $1.181^{*}$ & 0.834 & $1.271^{*}$ & $1.130^{*}$ & $1.285^{*}$ & $0.906^{*}$ & $0.791^{*}$ & $0.809^{*}$ \\
\hline$[65-80)$ & $0.212^{*}$ & $0.672^{*}$ & 0.863 & $1.978^{*}$ & $1.452^{*}$ & $1.663^{*}$ & $0.667^{*}$ & $0.479 *$ & $0.474^{*}$ \\
\hline$[80+)$ & $0.070^{*}$ & $0.522^{*}$ & 0.920 & $2.294^{*}$ & $1.610^{*}$ & $1.747^{*}$ & $0.573^{*}$ & $0.361^{*}$ & $0.297^{*}$ \\
\hline
\end{tabular}

\section{* Significance above $99 \%$}

$* *$ Significance above $95 \%$

\section{$* * *$ Significance above $90 \%$}

